\author{
UNIVERSIDADE DE SÃO PAULO \\ FACULDADE DE MEDICINA DE RIBEIRÃO PRETO \\ DEPARTAMENTO DE NEUROCIÊNCIAS
}

PAULA MARQUES LOURENÇO

\title{
ASPECTOS CLÍNICO-NEUROLÓGICOS DA NEUROPATIA MOTORA MULTIFOCAL
}

Ribeirão Preto 


\section{PAULA MARQUES LOURENÇO}

\section{Aspectos clínico-neurológicos da neuropatia motora multifocal}

Dissertação apresentada ao Departamento de Neurociências e Ciências do Comportamento da

Faculdade de Medicina de Ribeirão Preto da Universidade de São Paulo para obtenção do título de Mestre em Neurologia Clínica.

Mestrado Profissional em Neurologia / Neurociências

Orientador: Prof. Dr. Amilton Antunes Barreira

Ribeirão Preto 
Autorizo a reprodução e divulgação total ou parcial deste trabalho, por qualquer meio convencional ou eletrônico, para fins de estudo e pesquisa, desde que citada a fonte.

Lourenço, Paula Marques

Aspectos clínico-neurológicos da neuropatia motora multifocal, 2016.

63p. : il. ; $30 \mathrm{~cm}$

Dissertação de Mestrado Profissional, apresentada à Faculdade de Medicina de Ribeirão Preto/USP. Área de concentração: Neurologia/Neurociências.

Orientador: Antunes Barreira, Amilton.

1. Neuropatia Motora Multifocal. 2. Neuropatia Periférica.

3. Neuropatia inflamatória. 4. Bloqueio de Condução.

5. Imunoglobulina humana. 


\section{FOLHA DE APROVAÇÃO}

Paula Marques Lourenço

Aspectos clínico-neurológicos da neuropatia motora multifocal.

Dissertação apresentada ao Departamento de Neurociências e Ciências do Comportamento da Faculdade de Medicina de Ribeirão Preto da Universidade de São Paulo para obtenção do título de Mestre em Neurologia Clínica.

Mestrado Profissional em Neurologia / Neurociências

\section{Aprovado em:}

\section{Banca Examinadora}

Prof. Dr.

Instituição: Assinatura:

Prof. Dr.

Instituição:

Assinatura:

Prof. Dr.

Instituição: Assinatura: 


\section{RESUMO}

A neuropatia motora multifocal (NMM) é uma neuropatia inflamatória de baixa prevalência, 0,6/100.000 pacientes, caracterizada por uma fraqueza muscular progressiva, assimétrica e distal, sem comprometimento sensitivo. A NMM pode mimetizar a esclerose lateral amiotrófica (ELA), outras variantes da doença do neurônio motor e outras polineuropatias inflamatórias desmielinizantes crônicas, com início assimétrico. A diferenciação é importante, tendo em vista as especificidades da evolução e do tratamento das referidas neuropatias. O principal achado eletrofisiológico é o bloqueio de condução nervosa na ausência de anormalidades sensitivas. A fisiopatogenia da NMM é pouco conhecida. O frequente achado de anticorpos circulantes contra o monoassialogangliosídeo (GM1) é sugestivo de que possa haver seu comprometimento em alterações estruturais nodais e perinodais, com comprometimento multifocal da condução nervosa. O corolário desses distúrbios são paresias e paralisias, também de distribuição multifocal. A Imunoglobulina humana por via endovenosa em altas doses constitui o tratamento de escolha. Novas estratégias de tratamento alternativas são necessárias para prevenir fraqueza muscular permanente e incapacidade. Poucos estudos e revisões bibliográficas têm elucidado as características clínicas da NMM, com a ausência na literatura de publicações de série de casos nacionais. No presente estudo, a partir de uma revisão retrospectiva, serão avaliados os aspectos clínicos- eletrofisiológicos da NMM, a fim de se obter um maior entendimento da evolução da doença.

Palavras chave: neuropatia motora multifocal, neuropatias inflamatórias, bloqueio de condução. 


\begin{abstract}
The multifocal motor neuropathy (MMN) is an inflammatory neuropathy that has low prevalence $(0.6$ / 100,000 patients). It is characterized by progressive, asymmetric and distal muscle weakness without sensory impairment. The MMN can mimic amyotrophic lateral sclerosis (ALS), other motor neuron disease variants and other chronic inflammatory demyelinating polyneuropathy, with asymmetric start. Differentiation is important, given the specificities of the development and treatment of these neuropathies. The main electrophysiological finding is the nerve conduction block in the absence of sensory abnormalities. The pathophysiology of MMN is little known. The frequent finding of circulating antibodies against monoassialogangliosides (GM1) is suggestive that there may be their involvement in nodal and perinodal structural changes with multifocal impairment of nerve conduction. The corollary of these disorders is paresis and paralysis, with also multifocal distribution. The human immunoglobulin intravenously in high doses constitutes the treatment of choice. New alternative treatment strategies are needed to prevent permanent muscle weakness and disability. Few studies and literature reviews have elucidated the clinical features of MMN and there are no case series publications in the national literature. In this study, from a retrospective review, will be assessed clinic and electrophysiological features of $\mathrm{MMN}$ in order to obtain a greater understanding of disease progression.
\end{abstract}

Keywords: multifocal motor neuropathy, inflammatory neuropathies, conduction block. 


\section{LISTA DE ABREVIATURAS E SIGLAS}

AMAN: $\quad$ Neuropatia motora axonal aguda

AMSAN: Neuropatia sensitiva e motora aguda

BC: $\quad$ Bloqueio de condução

BHE: $\quad$ Barreira hemato-encefálica

CTDS: curva tensional diária simplificada

CVM: $\quad$ Contração voluntária máxima

DNM: Doença do neurônio motor

ELA: $\quad$ Esclerose Lateral Amiotrófica

GM1: monoassialogangliosídeo

IgIV: Imunoglobulina endovenosa

IgSC: $\quad$ Imunoglobulina subcutânea

LCR: Líquor cefalorraquidiano

CAM: $\quad$ Complexo de ataque à membrana

MADSAM: Neuropatia desmielinizante sensitiva e motora multifocal adquirida

MRC: $\quad$ Medical Research Council

NMM: $\quad$ Neuropatia motora multifocal

PAMC: $\quad$ Potencial de ação muscular composto

PAS: $\quad$ Potencial de ação sensitivo ou potenciais de ação sensitivos

PIDC: $\quad$ Polirradiculoneuropatia inflamatória crônica desmielinizante

SLS: $\quad$ Síndrome de Lewis-Sumner

VC: $\quad$ Velocidade de condução 


\section{SUMÁRIO}

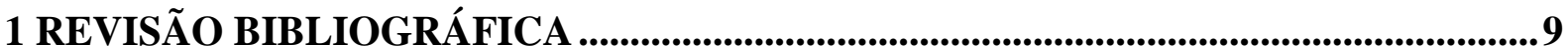

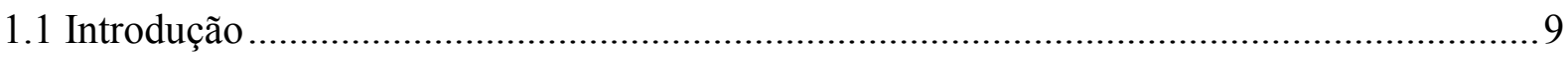

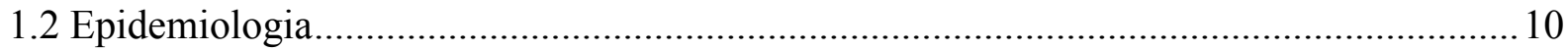

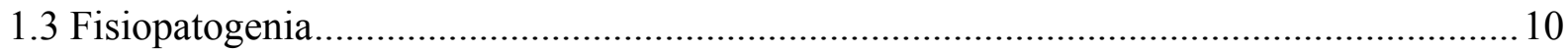

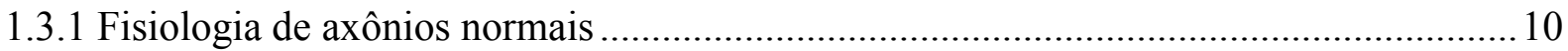

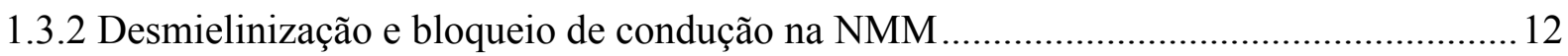

1.3.3 Alteração permanente do potencial de repouso da membrana ...................................... 14

1.3.4 Bloqueio de condução dependente de atividade.......................................................... 15

1.3.5 Canais de sódio nodais e bloqueio de condução na NMM ................................................ 16

1.3.6 Envolvimento seletivo de neurônios motores............................................................... 17

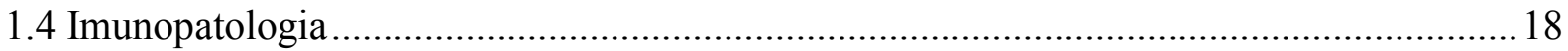

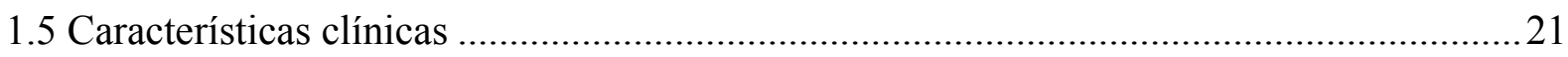

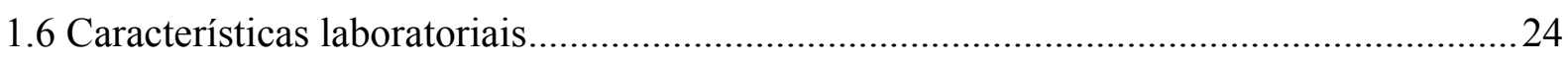

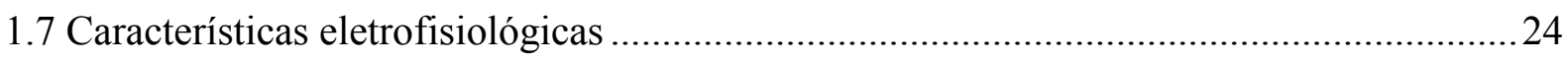

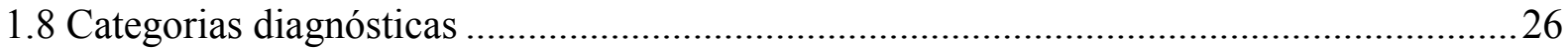

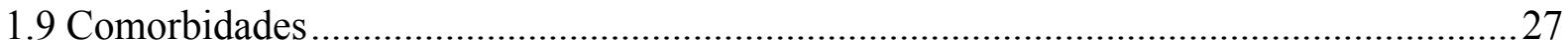

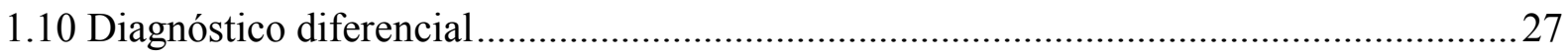

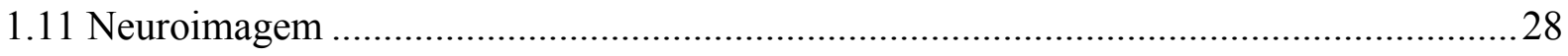

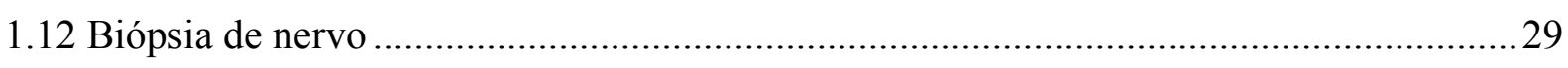

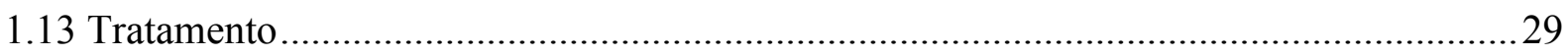

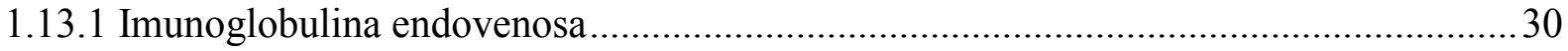

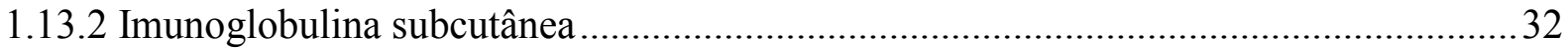

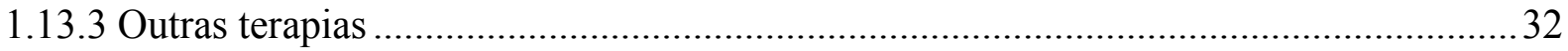

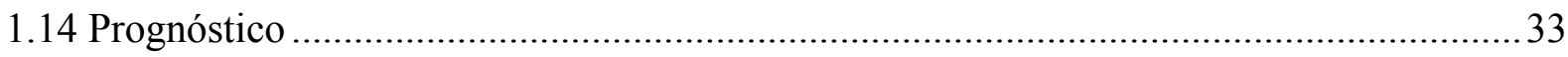

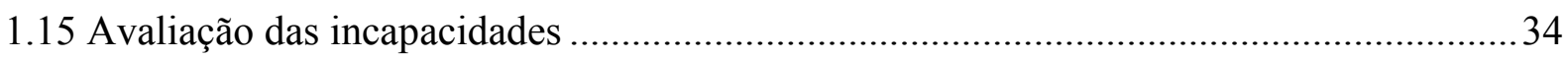

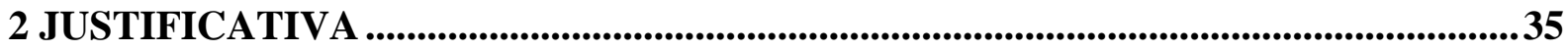

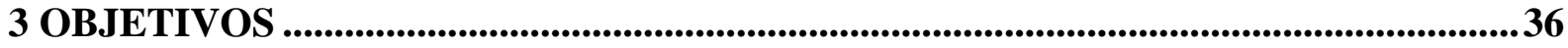

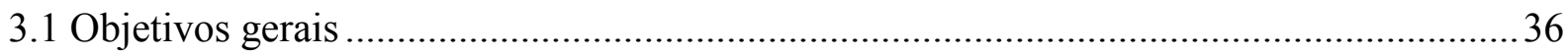


4 MATERIAIS E MÉTODOS

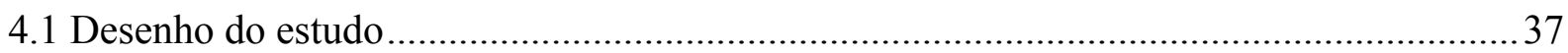

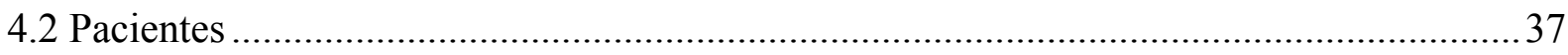

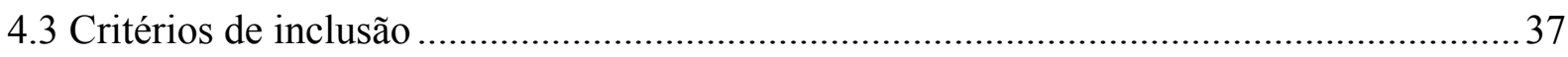

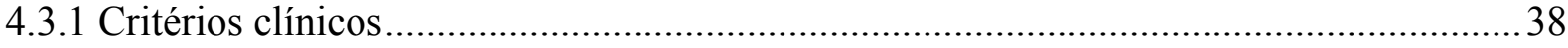

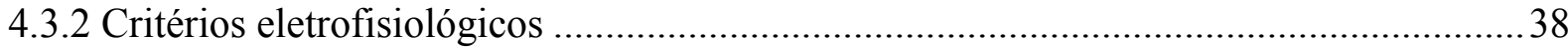

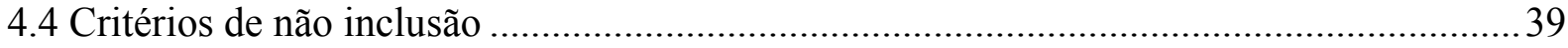

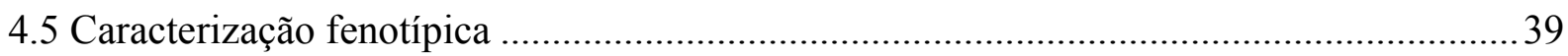

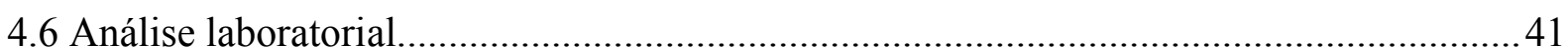

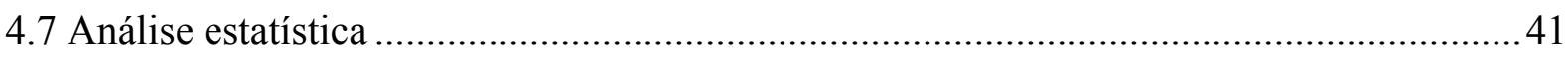

4.8 Aprovação pelo Comitê de Ética ................................................................................. 41

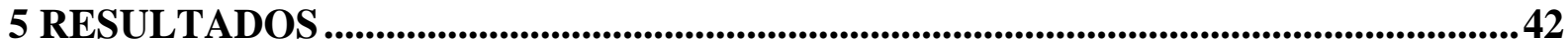

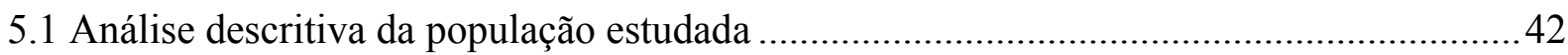

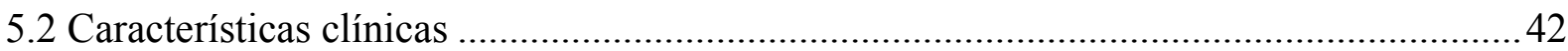

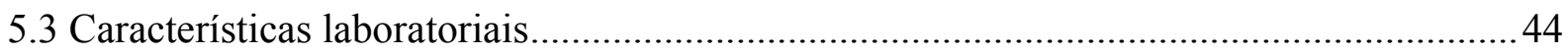

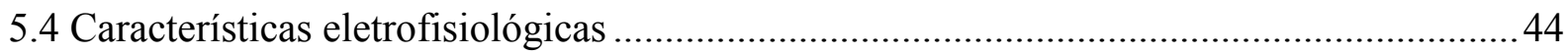

5.5 Características da evolução e do tratamento......................................................................46

6 DISCUSSÃO

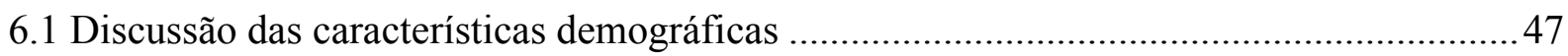

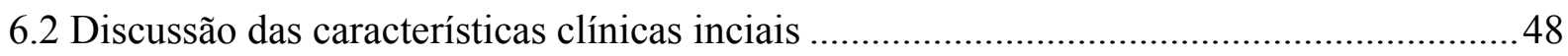

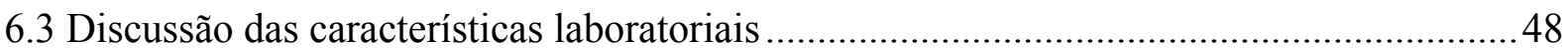

6.4 Discussão das características eletrofisiológicas ...............................................................49

6.5 Discussão das características da evolução e tratamento......................................................49

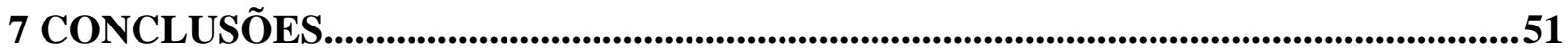

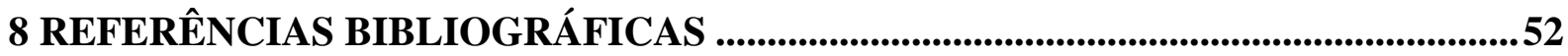




\section{REVISÃO BIBLIOGRÁFICA}

\subsection{Introdução}

Em 1985, na reunião anual da Academia Americana de Medicina Neuromuscular e Eletrodiagnóstica, Gareth Parry e Stephen Clarke (Parry e Clarke, 1988) apresentaram casos de três pacientes com neuropatia exclusivamente motora comprometendo os membros superiores. Até então o diagnóstico era de doença do neurônio motor, mas não havia sintomas bulbares ou de comprometimento do neurônio motor superior. O estudo da condução evidenciou bloqueios de condução importante em axônios motores. A condução sensitiva era normal. O quadro clínico-neurológico era de o de uma neuropatia motora múltipla. Os déficits motores ocorriam em distribuição de nervos periféricos, não tendo o padrão topográfico de acometimento de raízes como seria esperado nas doenças do neurônio motor. Em 1986, Roth e Magistris descreveram outro paciente com características clínicas e eletrofisiológicas semelhantes. Em 1988 foi proposta a denominação de neuropatia motora multifocal (NMM) por Alan Pestronk, que está consolidada na literatura médica. Pestronk constatou a presença de anticorpos antigangliosídeos (IgM GM1) no soro dos pacientes, além de referir uma resposta favorável ao uso de ciclofosfamida (Pestronk et al., 1988).

A imunoglobulina humana endovenosa (IgIV) é o tratamento de escolha e a sua eficácia foi demonstrada primeiramente por Kaji (Kaji, Shibasaki e Kimura, 1992) e Charles (Charles et al., 1992) ao reportarem três pacientes que obtiveram melhora clínica com a infusão da IgIV. Posteriormente, quatro ensaios randomizados duplo-cego controlados com placebo (Azulay et al., 1994; Van Den Berg et al., 1995; Federico et al., 2000; Leger et al., 2001) confirmaram este efeito benéfico. O mecanismo do efeito imunomodulador da IgIV é ainda mal compreendido. Embora possa compartilhar algumas características com a polirradiculoneuropatia inflamatória desmielinizante crônica (PIDC) e sua variante, a neuropatia desmielinizante sensitivo-motora multifocal adquirida (MADSAM - síndrome de Lewis-Sumner (SLS)), a NMM tem progressivamente sido reconhecida como uma entidade distinta. Faz parte do grupo das chamadas neuropatias imunomediadas crônicas. No entanto, persistem dúvidas principalmente sobre a fisiopatologia, a história natural, a evolução e o tratamento a longo prazo da doença (Guimaraes-Costa, Bombelli e Leger, 2013). 


\subsection{Epidemiologia}

Encontramos apenas um estudo que se refere a prevalência da NMM (Cats, Van Der Pol, et al., 2010). Esse estudo reuniu as casuísticas de NMM com bloqueio de condução de seis centros terciários da Holanda, que tinha uma população de 16,8 milhões de habitantes naquele ano. Os autores referem uma prevalência de pelo menos 0,6 pessoas por 100.000 habitantes, com base naquelas casuísticas. Considerando o mesmo critério diagnóstico, há predominância em homens (razão de sexo: 2,6:1) e a idade de início é de cerca de 40 anos. Oitenta por cento dos casos se iniciam entre 20 e 50 anos (Nobile-Orazio, 2001). No sexo masculino a doença se inicia mais precocemente, por volta dos 38 anos, enquanto nas mulheres, acontece em torno dos 45 (Cats, Van Der Pol, et al., 2010). Ao contrário da PIDC, o início da NMM não foi referido em pacientes com mais de 70 anos de idade (Vlam et al., 2012).

Pouco se sabe sobre a incidência e prevalência de NMM em crianças. Encontramos referência a apenas dois casos na literatura, com o início aos 6 e 12 anos de idade (Moroni et al., 2006; Ramdas et al., 2013).

\subsection{Fisiopatogenia}

O bloqueio de condução (BC) motor, fora de sítios de compressão, é o achado eletrofisiológico característico da NMM, embora não inteiramente específico. Os mecanismos fisiopatológicos por trás do bloqueio e das disfunções do nervo não foram completamente elucidados (Leger, Guimaraes-Costa e Iancu Ferfoglia, 2015).

\subsubsection{Fisiologia de axônios normais}

Cada axônio mielinizado está rodeado por uma bainha de mielina, que é interrompida a distâncias regulares pelo nó de Ranvier. Em axônios de grande diâmetro, a distância entre nós adjacentes é de cerca de 1-2 mm. Na região do nó de Ranvier, a membrana do axônio 
(axolema) está em contato direto com o fluido extracelular. $\mathrm{O}$ axônio entre dois nós adjacentes é subdividida em região paranodal (região onde a bainha de mielina está em contato com o axolema), justaparanodal (parte mais ampla do axônio) e internodal. Em um axônio mielinizado, um potencial de ação, gerado em um nó, se propaga a uma velocidade de 30-60 m/s (Franssen e Straver, 2013).

O axolema em neurônios motores de mamíferos contém vários tipos de canais voltagem-dependentes. Cada tipo de canal é encontrado em todos os segmentos do axônio, mas a sua densidade difere entre esses segmentos. Os canais de $\mathrm{Na}^{+}$são do tipo Nav1.6 e mantêm correntes transientes e persistentes. Os canais de $\mathrm{K}$ compreendem cinco tipos, mantendo correntes rápidas, intermediárias e lentas com propriedades de sobreposição. Os canais transientes de $\mathrm{Na}^{+}$geram $98-99 \%$ da corrente nodal de sódio e mantêm o potencial de ação. $\mathrm{O}$ canal contém um portão $\mathrm{M}$ e um portão $\mathrm{H}$. Durante o potencial de repouso da membrana, o portão $\mathrm{M}$ está fechado e o portão $\mathrm{H}$ aberto. Na despolarização, o portão $\mathrm{M}$ se abre, permitindo um influxo de íons de sódio. Depois de cerca de $1 \mathrm{~ms}$, o portão $\mathrm{H}$ se fecha e o canal torna-se inativado, extinguindo-se assim o potencial de ação. Os canais de $\mathrm{Na}^{+}$ persistentes permanecem abertos e determinam os potenciais de membrana para o limiar de excitação. (Franssen, 2014)

Os canais de $\mathrm{K}^{+}$rápidos têm uma alta densidade na região justaparanodal. Após a despolarização, eles se abrem rapidamente, cerca de 0,5-1,0 ms após a abertura do canal transiente de $\mathrm{Na}^{+}$. Isso provoca a passagem do íon $\mathrm{K}^{+}$para o exterior do neurônio o que induz o potencial de membrana a retornar ao seu valor de repouso. Os canais lentos de $\mathrm{K}^{+}$estão concentrados no nó e se abrem lentamente - dezenas de ms - após a despolarização. Os canais de íons controlados por nucleotídeo cíclico (canais $\mathrm{HCN}$ ) estão localizados na região internodal e a sua ativação pode ser observada cerca de $100 \mathrm{~ms}$ após a hiperpolarização, com a passagem de uma corrente de cátions para seu interior o que torna o potencial de membrana menos negativo. (Reid et al., 1999)

Os impulsos se propagam pelo fato de que, em um nó ativo, os canais transientes de $\mathrm{Na}^{+}$estarão abertos e os íons de $\mathrm{Na}^{+}$irão fluir para dentro do axônio. Essa corrente de ação despolariza a membrana que, por sua vez, induz mais aberturas de canais de $\mathrm{Na}^{+}$, seu influxo e sua despolarização. O potencial de ação induz uma corrente que retorna para o exterior e deixa o axônio com uma corrente de condução que irá ativar o próximo nó de Ranvier. Neste nó, a corrente de condução deixa cargas positivas no seu interior e repele cargas positivas a partir do seu lado de fora, despolarizando-a (nenhum íon passa pelo axolema daquele nó, desde que os seus canais de $\mathrm{Na}^{+}$estejam fechados). Quando esse nó é suficientemente 
despolarizado, tais canais de $\mathrm{Na}^{+}$se abrem e a corrente de condução se transforma em corrente de ação, que gerará o potencial de ação. O potencial de ação no nó de Ranvier precedente extingue-se com a inativação do canal de $\mathrm{Na}^{+}$. Qualquer interrupção desta corrente irá causar um bloqueio de condução (BC) (Franssen, 2014).

\subsubsection{Desmielinização e bloqueio de condução na NMM}

A desmielinização pode resultar em bloqueio de condução (BC) por vários mecanismos (Kaji, 2003). Primeiramente, em um nó a ser ativado, a área dos axônios nos espaços internodais é muito maior, comparada à dos nós de Ranvier. Isto faz com que haja perda da corrente devido à desmielinização. Assim, se a densidade da corrente de condução não for suficiente para abrir o número necessário de canais de $\mathrm{Na}^{+}$no nodo a ser ativado, o potencial de ação não é gerado e a propagação do impulso estará bloqueada. Se a densidade da corrente de condução é reduzida, sendo, entretanto, suficiente para a geração de impulso, a condução será mantida, porém lentificada. Isso ocorre porque a corrente tem que fluir por mais tempo até que um número suficiente de canais Nav1.6 seja ativado e possa gerar um potencial de ação. Assim, na desmielinização, o BC e a redução da velocidade de condução constituem parte de um mesmo espectro. Em circunstâncias fisiológicas desfavoráveis, tais como o aumento da temperatura, a redução da velocidade pode se transformar em um BC (Franssen, 2014).

Em segundo lugar, se as camadas de mielina das regiões paranodais são destruídas, os canais de $\mathrm{Na}^{+}$do nó de Ranvier podem se dispersar no axolema. Isso também pode induzir um $\mathrm{BC}$, em decorrência da redução da densidade da corrente de ação. Em terceiro lugar, a exposição de canais rápidos justaparanodais de $\mathrm{K}^{+}$pela desmielinização faz com que eles se tornem ativos e a repolarização pode se iniciar antes que a despolarização atinja o limiar de excitabilidade. Além disso, o potencial de repouso da membrana pode se tornar mais negativo, mais distante do limiar de excitabilidade. (Franssen e Straver, 2013)

A desmielinização na NMM foi sugerida pelo achado de uma redução marcante da velocidade de condução (VC) compatível com desmielinização em segmentos com BC motor. Além disso, estudos de excitabilidade nos nervos do antebraço em cinco pacientes com NMM com BC, mostraram um aumento da condutância da mielina compatível com desmielinização (Van Asseldonk et al., 2003). Considerando os achados de desmielinização, admite-se que a 
propagação do impulso seja restaurada por um aumento da expressão do canal Nav1.6 ao longo de todo o segmento do axônio desmielinizado. Os canais de Nav1.6 geram um grande influxo contínuo de $\mathrm{Na}^{+}$, de modo que esta condução provoca grande acúmulo de $\mathrm{Ca}^{+2} \mathrm{e}^{+}$, com consequente degeneração axonal (Waxman, 2006).

Finalmente, biópsias de nervo estudos patológicos mostraram evidências de desmielinização (Kaji et al., 1993) e um grau variável de degeneração e perda de fibras. Poucas fibras grossas foram encontradas, com um aumento de fibras remielinizadas e brotamentos axonais. (Taylor et al., 2004). Para Taylor, todavia, com base nos seus achados de biópsia, um bloqueio de condução seria devido a um ataque mediado por anticorpos contra componentes do axolema no nó de Ranvier.

Uma característica típica da desmielinização em experimentos com animais é o desenvolvimento de $\mathrm{BC}$ quando a temperatura é discretamente aumentada, um fenômeno conhecido como bloqueio pelo calor (Rasminsky, 1973). O bloqueio pelo calor resulta da combinação de fatores desfavoráveis, prejudicando a geração de impulso no nó a ser ativado. A densidade de corrente de condução é reduzida devido à desmielinização (citado acima). $\mathrm{O}$ aumento da temperatura encurta o tempo de abertura do canal de $\mathrm{Na}^{+}$no nó ativo que, por sua vez, origina uma diminuição adicional na corrente de condução no nó que tem de ser ativado (Schwarz e Eikhof, 1987). O aumento da temperatura induz a ativação mais rápida dos canais rápidos de $\mathrm{K}^{+}$que se opõe à geração do potencial de ação. Se o BC na NMM fosse causado por desmielinização, ele deveria ser induzido pelo calor. Os pacientes com NMM, no entanto, queixam-se de uma piora dos sintomas motores com o frio e isto não é compatível com efeito da desmielinização (Schwarz e Eikhof, 1987).

As queixas de piora motora com o frio (paresia com o frio) foram referidas pela primeira vez em um estudo de caso (Kaji, 2003). Posteriormente, os sintomas de paresia com frio e com o calor foram estudados em pacientes com NMM, com PIDC, doença do neurônio motor (DNM) e polineuropatia axonal crônica idiopática (Straver, Van Asseldonk, et al., 2011). Os sintomas de paresia associada ao frio ocorreram com mais frequência na MMN (83\%) e a probabilidade de se apresentarem déficits de força muscular com o frio foi 4-6 vezes maior na NMM do que em outros pacientes (Franssen, 2014).

Como a paresia associada ao frio não pode ser explicada pela desmielinização, foi aventada a hipótese de que ela estaria relacionada a lesões inflamatórias do nervo onde axônios são despolarizados, mas capazes de conduzir impulsos à temperatura ambiente (Kaji, 2003). No local destas lesões, a redução da atividade da bomba de $\mathrm{Na}^{+} / \mathrm{K}^{+}$devido ao resfriamento pode induzir uma despolarização adicional e bloqueio pela despolarização 
porque provoca a inativação do canal de $\mathrm{Na}^{+}$. Alguns experimentos dão suporte a esta hipótese (Priori et al., 2005). Estudo sobre excitabilidade evidenciou que o resfriamento gradual de $37^{\circ}$ a $15^{\circ} \mathrm{C}$ do nervo mediano em indivíduos normais resultou em despolarização axonal progressiva, melhor explicada pela redução da atividade da bomba $\mathrm{Na}^{+} / \mathrm{K}^{+}$. Além disso, em alguns nervos de pacientes portadores de NMM foram encontrados axônios permanentemente despolarizados.

Alternativamente, a piora motora associada ao frio na NMM pode ser causada por um $\mathrm{BC}$ em fibras musculares reinervadas, porque diante da reinervação tais fibras, ao contrário do músculo normal, podem desenvolver despolarização durante o resfriamento (Rack e Fox, 1987).

\subsubsection{Alteração permanente do potencial de repouso da membrana}

Mudanças permanentes no potencial de repouso devido a um processo fisiopatológico podem prejudicar a propagação do impulso e, portanto, induzir um BC. Isso ocorre porque a despolarização resulta em um aumento da porcentagem de canais de $\mathrm{Na}^{+}$transientes inativados e hiperpolarizados, sendo necessária uma corrente de condução maior para gerar potenciais de ação. (Franssen, 2014). Essas possibilidades foram investigadas em pacientes com NMM ao se aplicar correntes de polarização focais no local do BC e ao avaliar o seu efeito sobre o PAMC evocado proximal ao referido local (Priori et al., 2005). Em dois nervos este PAMC aumentou durante a aplicação de uma corrente hiperpolarizante. Isto foi considerado consistente com o desaparecimento de bloqueio em axônios que estavam despolarizados antes da aplicação da corrente de polarização. Em três outros nervos o PAMC aumentou após a aplicação de uma corrente despolarizante, o que sugere que o bloqueio foi causado pela hiperpolarização focal de axônios.

Estudos de excitabilidade em pacientes com NMM, realizados em sítios distais com bloqueio de condução motor, evidenciaram anormalidades semelhantes aos encontrados durante a aplicação de corrente hiperpolarizante, o que sugere que os axônios são hiperpolarizados na NMM (Kiernan et al., 2002). Para explicar a hiperpolarização focal, os autores aventaram a hipótese de que, no local da lesão com bloqueio de condução, a atividade da bomba de $\mathrm{Na}^{+} / \mathrm{K}^{+}$está bloqueada. Este bloqueio ocorre devido à presença de edema ou de anticorpos que causam uma despolarização permanente e contínua causando um influxo 
persistente de $\mathrm{Na}^{+}$possivelmente através de canais de $\mathrm{Na}^{+}$. Nas porções adjacentes do axolema saudável, foi sugerido que os íons de $\mathrm{Na}^{+}$acumulados são removidos por um aumento da atividade da bomba de $\mathrm{Na}^{+} / \mathrm{K}^{+}$, resultando em hiperpolarização focal. Isso ocorre porque cada ciclo da bomba remove três íons de $\mathrm{Na}^{+}$do axônio e entram apenas dois íons de $\mathrm{K}^{+}$de volta para o axônio, causando assim um prejuízo líquido de carga positiva. A despolarização axonal permanente pode induzir um aumento em cascata de influxo de $\mathrm{Na}^{+}$ através de canais de $\mathrm{Na}^{+}$persistentes, gerando um acúmulo de $\mathrm{Na}^{+}$dentro do axônio. Esse acúmulo causa a reversão do trocador $\mathrm{Na}^{+} / \mathrm{Ca}^{+2}$ do axônio a fim de remover o excesso de ions de $\mathrm{Na}^{+}$em troca de íons de $\mathrm{Ca}^{+2}$. Isso provoca um acúmulo intra-axonal de $\mathrm{Ca}^{+2} \mathrm{e}$, consequentemente, uma degeneração axonal mediada por $\mathrm{Ca}^{+2}$ (Waxman et al., 1994). Especulou-se posteriormente que essa cascata poderia ser evitada por inibidores do complemento ou inibidores da calpaina (Mcgonigal et al., 2010).

\subsubsection{Bloqueio de condução dependente de atividade}

Foram observadas alterações musculares durante a CVM. Os BC foram monitorados antes e comparados com os músculos contralaterais não afetados e em pacientes com esclerose lateral amiotrófica (ELA). Durante 60 segundos de CVM, os músculos afetados desenvolveram fadiga. Houve uma redução significativamente menor da força ao final da contração comparada com a força inicial, diferentemente do que ocorreu com os controles. Além disso, depois da CVM, a razão da amplitude dos PAMCs após estimulação proximal e distal ficou reduzida transitoriamente. Tal ocorreu ao se compararem os resultados nos músculos afetados antes da CVM, que não se reduziu nos músculos dos controles. Os autores concluíram que o bloqueio de condução pós CVM pode desempenhar um papel importante na NMM, causando fadiga muscular (Kaji et al., 2000). Mais recentemente, um novo estudo (Straver, Van Den Berg, et al., 2011) tinha o objetivo de confirmar a relação entre BC dependente de atividade e fraqueza em pacientes com NMM. Foi empregada estimulação elétrica supra-máxima em segmentos de nervo dos pacientes com NMM. Foram excluídos nervos com acentuada perda axonal. Não foi encontrada mudança significativa após a CVM: não houve indução do $\mathrm{BC}$ dependente de atividade. Em segmentos com o BC, a CVM induziu um aumento da duração do PAMC. Conclui-se, portanto, que a CVM induziu uma dispersão temporal, porém nenhum $\mathrm{BC}$ dependente de atividade. 


\subsubsection{Canais de sódio nodais e bloqueio de condução na NMM}

Danos a canais de $\mathrm{Na}^{+}$dependentes de voltagem no nó de Ranvier podem resultar em $\mathrm{BC}$ devido à perda da corrente de ação. Embora a ocorrência deste mecanismo não tenha sido comprovada na NMM, tal teoria tem suporte em alguns experimentos. O gangliosídeo GM1 é expresso no axolema nodal e metade dos pacientes com NMM têm anticorpos anti-GM1. Isso sugere a possibilidade de uma agressão imunomediada às moléculas de suporte nodais (Vlam et al., 2012). A injeção de anti-GM1 de um paciente com NMM no nervo ciático de ratos induziu BC, mas pouca desmielinização. Tais achados sugerem que o BC tenha sido causado por dano nodal do canal de $\mathrm{Na}^{+}$(Santoro et al., 1992). A aplicação de uma elevada concentração de soro anti-GM1 em axônios mielinizados de ratos resultou em um aumento das correntes rápidas de $\mathrm{K}^{+}$. Esses resultados indicam que os anticorpos anti-GM1 podem expor dos canais rápidos de $\mathrm{K}^{+}$por desmielinização justaparanodal. A adição de complemento a esses anticorpos podem formar complexos anticorpo-complemento que bloqueiam os canais de $\mathrm{Na}+$. Isso leva a uma ruptura da membrana no nó de Ranvier (Takigawa et al., 1995).

Em modelos de animais com neuropatia motora axonal aguda (AMAN), danos aos canais de $\mathrm{Na}^{+}$nodais foram observados por imunocoloração. Em um primeiro estudo (Susuki et al., 2007) foi evidenciado uma perturbação do funcionamento dos canais de $\mathrm{Na}^{+}$após a deposição de anticorpos anti-GM1. As alterações do canal ocorrem como uma consequência da interrupção da interação de axônios e células de Schwann, mediada por complemento. Em um estudo posterior (Susuki et al., 2012) foi evidenciado um BC reversível após a infusão de anti-GM1. Posteriormente houve uma deposição de imunoglobulina nesses segmentos. Tais achados sugerem que o anticorpo anti-GM1 associado ao complemento pode causar desmielinização e danos aos canais de $\mathrm{Na}^{+}$nodais. Considera-se provável que os danos aos aglomerados de canais de $\mathrm{Na}^{+}$sejam secundários à lesão do axolema ou às moléculas de suporte pelo complexo de ataque a membrana (CAM). Não foi comprovado que o anticorpo anti-GM1 tenha ação direta contra a proteína do canal de $\mathrm{Na}^{+}$(Santoro et al., 1992; Franssen, 2014).

Não se pode extrapolar o conjunto de resultados acima referidos para os pacientes com NMM. Pelo menos três razões devem ser consideradas. As altas concentrações de anticorpos anti-GM1 usadas nos estudos têm alta probabilidade não ocorrerem nos pacientes com NMM. As injeções intraneurais se associam a um efeito mecânico ausente na NMM. Não está claro se a AMAN pode ser usada como analogia para a NMM. A AMAN é uma neuropatia aguda 
com anticorpos $\mathrm{IgG}$, enquanto que a NMM é uma neuropatia crônica com anticorpos IgM (Franssen, 2014).

\subsubsection{Envolvimento seletivo de neurônios motores}

O comprometimento seletivo de axônios motores na NMM não está bem compreendido. O fascículo do nervo periférico onde ocorrem as lesões na NMM pode conter axônios motores e sensitivos (Sunderland, 1990). Apenas os nervos com uma perda proeminente de axônio motor também apresentam axônios sensitivos afetados (Delmont et al., 2009). Um estudo para explicar esta seletividade abordou as diferenças das propriedades imunológicas e de canais iônicos entre axônios motores e sensitivos. A quantidade de gangliosídeo pode ser diferente entre fibras motoras e sensitivas. Raízes motoras lombares humanas mielinizadas contêm mais GM1 do que fibras de raízes sensitivas, sugerindo que fibras motoras são mais vulneráveis aos anticorpos antigangliosideos, devido a uma maior quantidade de antígeno (Ogawa-Goto et al., 1992). Outros estudos, no entanto, não deram suporte a tais achados. Em um de tais estudos foi evidenciado que os anticorpos anti-GM1 se ligam igualmente a fibras de raízes motoras e sensitivas (Gong et al., 2002). Outro demonstrou que anticorpos anti-GM1 ligavam-se mais fortemente em GM1 de raízes sensitivas do que motoras (Ogawa-Goto e Abe, 1998). Alternativamente, axônios motores podem se tornar alvos seletivos porque seus gangliosídeos têm uma composição molecular um pouco diferente do que um mesmo gangliosídeo de fibras sensitivas. Uma molécula de gangliosídeo consiste em uma porção de ceramida localizada na membrana bilipídica e uma porção de açúcar extracelular. A porção de ceramida dos gangliosídeos GM1 das raízes motoras contém uma quantidade menor de lipídeos de cadeia longa do que a dos gangliosídeos das raízes sensitivas. Essa diferença, todavia, não explica o envolvimento motor seletivo, porque os anticorpos se ligam aos resíduos de açúcar e não à porção de ceramida. É possível que uma porção diferente de ceramida em axônios motores possa influenciar a configuração 3-D da porção extracelular do açúcar, tornando mais susceptível a ligação do anticorpo anti-GM1 (Ogawa-Goto et al., 1990).

As diferenças nas propriedades biofísicas podem tornar os axônios motores mais vulneráveis a desenvolver $\mathrm{BC}$ do que os sensitivos quando um nervo contendo axônios motores e sensitivos é afetado pela doença. Estudos de excitabilidade mostraram que axônios 
sensitivos normais têm uma constante de tempo de duração $\mathrm{x}$ intensidade maior que axônios motores. Essa constante é derivada da relação entre a intensidade e duração do estímulo para gerar um potencial de ação. Além disso, fibras sensitivas apresentam uma Rheobase menor. A Rheobase é a corrente mínima, aplicada com uma longa duração, que gera um potencial de ação. Os axônios sensitivos têm uma maior atividade dos canais HCN do que axônios motores normais (Lin et al., 2002). Uma maior constante de tempo de duração x força reflete uma corrente de $\mathrm{Na}^{+}$mais persistente, causando um baixo limiar para a geração de impulso. Para a manutenção da contração muscular é necessário que axônios motores disparem entre 20$50 \mathrm{~Hz}$. Os axônios sensitivos, por outro lado, têm de conduzir a taxas de impulsos a $200 \mathrm{~Hz}$, a fim de transmitir a informação sensitiva de forma confiável. Foi aventado que três fatores são necessários para manter a maior frequência de disparo de axônios sensitivos. O baixo limiar para a geração de impulso, que é assegurado por sua corrente $\mathrm{Na}^{+}$persistente. A regulação positiva das bombas de $\mathrm{Na}^{+} / \mathrm{K}^{+}$para a correção de gradientes de concentração iônica perturbados por altas taxas de impulso. A regulação positiva de canais HCN para neutralizar a hiperpolarização causada por estas bombas adicionais (Bostock e Rothwell, 1997; Hofmeijer et al., 2013).

Quando o fator de segurança é reduzido, por exemplo, devido à desmielinização, a corrente de condução pode ficar bloqueada em axônios motores. Mas pode ser mantida em axônios sensitivos porque a sua maior corrente de $\mathrm{Na}^{+}$persistente contribui para a sua excitabilidade. Nesse caso, somente axônios motores podem desenvolver BC. Como axônios motores têm uma menor atividade de canais $\mathrm{HCN}$, a sua hiperpolarização é menos neutralizada por esse canal (Burke, Kiernan e Bostock, 2001).

\subsection{Imunopatologia}

Vários trabalhos têm sido publicados nos últimos anos sobre o papel dos gangliosídeos no nó de Ranvier, funcionando como potenciais antígenos-alvo nas neuropatias motoras, especialmente nas variantes axonais da síndrome de Guillain-Barre e na NMM (Yuki, 2013). Os anticorpos antigangliosideos e o papel que desempenham na patogênese da AMAN, AMSAN, e mais provável NMM, podem ser chaves para entender a fisiopatogenia dessas doenças. 
Conforme discutido acima, o GM1 é expresso em vários locais, localizando- se tanto no axolema, quanto na mielina dos nervos periféricos, sendo encontrado em maior abundância nos nós de Ranvier e na região paranodal adjacente (Willison e Yuki, 2002). Há uma maior concentração de GM1 em domínios ricos em colesterol da membrana plasmática. As funções desses domínios não são completamente compreendidas, a mais relevante parece ser uma estabilização paranodal e agrupamento de canais iônicos (Susuki et al., 2007). O GM1 facilita a manutenção das junções de adesão através da estabilização paranodal, e também funciona como uma âncora para os canais de $\mathrm{K}^{+}$, concentrando os canais de $\mathrm{Na}^{+}$. Essas funções são necessárias para a propagação e manutenção da velocidade de condução do potencial de ação. A perturbação dessas funções induz a falha de condução em todas as regiões paranodais (Leger, Guimaraes-Costa e Iancu Ferfoglia, 2015).

Há muito debate sobre se os anticorpos antigangliosideos são auto-anticorpos primários que provocam neuropatias ou se são apenas biomarcadores resultantes da sequência de eventos que conduz à lesão do nervo. Estudos sugerem que os anticorpos antigangliosideos podem ter um papel patogênico na NMM. Em 2011, um de tais estudos mostrou que os anticorpos IgM anti-GM1 proveniente de soro dos pacientes com NMM se ligavam ao GM1 e ativavam a cascata do complemento in vitro (Yuki et al., 2011). O acúmulo de depósitos de complemento era altamente correlacionado com o título de anticorpo anti-GM1. Além disso, com a infusão da IgIV, houve a redução da deposição desses componentes do complemento de forma dose-dependente. Os autores postularam que a lesão induzida por IgM era complemento-mediada e ocorria nos nós de Ranvier em nervos periféricos, gerando o $\mathrm{BC}$ e a fraqueza muscular.

Apesar de não existir modelo animal de NMM, o mecanismo de dano do anticorpo contra GM1 poderia ser semelhante ao observado no modelo de coelho com AMAN. Nesse modelo o anticorpo anti-GM1 ativa a cascata de complemento para a produção de um complexo de ataque a membrana (CAM). Esse complexo afeta a integridade da membrana, comprometendo posteriormente as regiões internodais do nervo. Há interrupção dos canais de $\mathrm{Na}^{+}$, o que permite a ligação de mais anticorpos no axolema (O'hanlon et al., 2003). O uso de inibidores do complemento anula o dano a integridade da membrana em modelos animais, oferecendo mais evidências de que a doença seja complemento-dependente (Leger, Guimaraes-Costa e Iancu Ferfoglia, 2015).

Mais recentemente, outros estudos testaram se o soro de doentes com NMM pode atravessar a barreira hemato-encefálica (BHE). Há uma diminuição da proteína claudina-5 nos soros dos pacientes com NMM e redução da resistência elétrica transendotelial de nervos 
periféricos. Este efeito foi revertido após a aplicação de um anticorpo neutralizante do fator de crescimento endotelial (anti-VEGF). Conclui-se que o soro de pacientes com NMM pode perturbar o funcionamento da BHE ao provocar a secreção de VEGF em células endoteliais de nervos periféricos. A ruptura da BHE permitiria a entrada de células inflamatórias circulantes no nervo periférico (Shimizu et al., 2014).

A presença de anticorpos anti-GM1 tem sido documentada nas primeiras descrições de NMM, mas a sua prevalência não é semelhante nas diversas séries (Nobile-Orazio, 2001). Há diferenças metodológicas, sem que haja um padrão-ouro para a mensuração dos títulos desses anticorpos. Em ensaios imunoenzimáticos (ELISA) não tem sido encontrada uma grande proporção de pacientes com NMM com títulos significativos de anticorpos anti-GM1. Desconhece-se se esses pacientes têm títulos baixos desses anticorpos no soro que não são detectáveis por ELISA ou se têm outros anticorpos dirigidos contra antígenos-alvo. A clínica característica de pacientes com e sem anticorpos anti-GM1 não difere, e a resposta ao tratamento é semelhante nos dois grupos (Leger et al., 2008). Contudo, os achados de outros complexos antigangliosideos, que podem aumentar ou reduzir a ligação ao GM1, também pode fornecer uma explicação para esta variação (Nobile-Orazio, Giannotta e Briani, 2010). Vários estudos foram destinados a aumentar a detecção de auto-anticorpos na NMM. O grupo de Pestronk encontrou resultados com o anticorpo IgM ligando-se a um dissacarídeo de heparina NS6S, que foi associado a síndromes motoras e ocorreu com uma frequência semelhante da ligação de IgM a GM1 (Pestronk, Chuquilin e Choksi, 2010). Os autores concluíram que, ao se realizar o teste da ligação de IgM-antiGM1 a NS6S, pode-se aumentar a frequência de anticorpos IgM em neuropatias motoras de 43\% a 64\%. Em outro estudo, foi encontrado no soro de pacientes com NMM um anticorpo anti GM1 que se liga a uma mistura de lipídeos contendo GM1, galactocerebrósideo e colesterol. Este anticorpo lipídicodependente pode explicar, em parte, a grande proporção de pacientes com MMN que são soronegativos para os anticorpos anti-GM1 (Pestronk et al., 1997).

A ativação de anticorpos específicos contra GM1 a partir de células B explicaria aumento dos títulos, mas o mecanismo subjacente desta ativação ainda deve ser esclarecido. Os anticorpos anti-GM1 na sindrome de Guillain Barré estão associadas a infecções por microrganismos, mais comumente o Campylobacter jejuni, que expressam estruturas de gangliósidos semelhantes na sua superfície dentro de alguns dias ou semanas antes do início da doença. A infecção por C. jejuni pode causar ativação específica de células B para a produção de anticorpos contra GM1, caracterizando o processo mimetismo molecular. 
Resultados de estudos sorológicos em pequena escala não conseguiram documentar associação semelhante com a NMM (Terenghi et al., 2002).

A gamopatia monoclonal de significado indeterminado também está associada ao aumento dos títulos de IgM anti-GM1, sugerindo que mudanças intrínsecas nos clones de células B, pode ser a base da NMM (Eurelings et al., 2001). Tomadas em conjunto, as infecções com C. jejuni e alterações pré-malignas de células $\mathrm{B}$ não parecem explicar o aumento dos títulos de IgM anti- GM1 na maioria dos casos de NMM. Isso sugere a participação de mecanismos desconhecidos de ativação de células B na NMM (Muley e Parry, 2012).

Outro estudo relatou uma maior frequência do antígeno leucocitário humano (HLA) classe II DR B1/15 em pacientes com NMM, o que pode sugerir uma predisposição genética e uma via patogênica semelhante a outras doenças tais como a esclerose múltipla e PIDC. Infelizmente, até o presente, uma correlação com este HLA e idade de início, o curso ou a gravidade da doença não foi encontrado (Sutedja et al., 2010).

\subsection{Características clínicas}

A NMM é caracterizada pelo comprometimento assimétrico da força muscular, predominantemente distal, com topografia correspondente a territórios inervados por nervos periféricos individuais. Não há evidência de perda sensitiva. A fraqueza geralmente começa nos músculos do antebraço ou da mão, mas os primeiros sintomas podem se apresentar distalmente nos membros inferiores em 20-30 \% dos casos. Em cerca de 5\% dos casos o início ocorre nos braços. Em um relato de 88 pacientes com NMM não houve início da fraqueza na parte proximal dos membros inferiores. $O$ início mais frequente é na mão dominante (Cats, Van Der Pol, et al., 2010). Os critérios clínicos e de suporte para o diagnóstico da NMM encontram-se na tabela 1 e 2 respectivamente.

A progressão de sinais e sintomas sensitivos foi referida. Tais achados são corroborados por estudos eletrofisiológicos que evidenciaram redução da amplitude dos PAS e discreta redução das VCS, ambos respeitando o território de nervos sensitivos. Essas alterações neurofisiológicas podem ou não estar associadas a sinais e sintomas sensitivos ao longo do curso da NMM (Delmont et al., 2009; Lambrecq et al., 2009; Lievens et al., 2009). Queixa de parestesia transitória pode ser referida por alguns pacientes, embora, geralmente, 
não seja acompanhada por perda objetivável da sensibilidade, a não ser por discreta redução distal da palestesia nos membros inferiores. A hipopalestesia distal foi encontrada em $22 \%$ dos pacientes em uma série de pacientes com NMM (Cats, Jacobs, et al., 2010). Essa hipopalestesia foi associada a uma duração mais longa da doença, quando comparada à de pacientes sem comprometimento sensitivo. O comprometimento sensitivo tardio pode se dever ao fato de que as fibras sensitivas são menos vulneráveis ao dano causado por anticorpos IgM anti-GM1 (Harschnitz et al., 2014).

Tabela 1. Critérios maiores para o diagnóstico clínico

1-Fraqueza lentamente progressiva ou com períodos de estabilização, focal, assimétrica (diferença de um na escala MRC se força maior que três e diferença de dois se força é menor ou igual a três), com comprometimento motor de ao menos dois nervos, com mais de um mês de evolução (usualmente seis meses).

2-Ausência de anormalidades sensitivas objetivas, exceto por discreta anormalidade palestésica em MMII.

Fonte: Critérios Diagnósticos Clínicos (European Federation of Neurological Societies/Peripheral Nerve Society guideline on management of multifocal motor neuropathy. Report of a joint task force of the European Federation of Neurological Societies and the Peripheral Nerve Society--first revision, 2010).

Os nervos mais comprometidos são os ulnares, medianos, radiais e tibiais. Os músculos apresentam variados padrões de fraqueza. Isso reflete o padrão de irregularidade de comprometimento do nervo. Um estudo demonstrou que 54\% dos pacientes apresentavam diferentes intensidades dos déficits de força muscular quando se comparam músculos inervados por um ramo terminal comum. Foram encontrados diferentes padrões de fraqueza muscular para a extensão dos dedos, refletindo provavelmente uma vulnerabilidade de ramos terminais do nervo interrósseo posterior (Slee, Selvan e Donaghy, 2007). Nos primeiros anos de doença, a atrofia muscular geralmente é discreta, quando comparada à fraqueza muscular. Entretanto, pacientes com duração prolongada da doença podem apresentar uma intensa atrofia muscular. Um déficit motor acentuado com discreta ou nenhuma amiotrofia pode ser considerado uma característica da doença e da expressão clínica do BC. Sintomas motores de cãibras e fasciculações são referidos em mais da metade dos pacientes e são utilizados como critérios de suporte ao diagnóstico.

Os reflexos tendinosos são habitualmente hipoativos ou ausentes nos músculos enfraquecidos. Contudo, reflexos normais podem ser encontrados em até $8 \%$ dos pacientes e 
reflexos vivos podem estar presentes em 9\%. Reflexos vivos, sem policinesia, podem ser encontrados mesmo em músculos afetados (Vlam et al., 2012).

Tabela 2. Critérios de suporte para diagnósticos clínicos.

1- Acometimento predominantemente de membros superiores $(10 \%$ dos casos se iniciam em membros inferiores).

2- Reflexos reduzidos ou ausentes em membros inferiores (reflexos vivos são relatados, porém não excluem o diagnóstico).

3- Ausência de acometimento de nervos cranianos (paralisia do XII par já foi relatada).

4- Câimbras e fasciculações nos membros afetados.

5- Resposta ao tratamento imunomodulador, com melhora da incapacidade e força.

Fonte: Critérios Diagnósticos Clínicos (European Federation of Neurological Societies/Peripheral Nerve Society guideline on management of multifocal motor neuropathy. Report of a joint task force of the European Federation of Neurological Societies and the Peripheral Nerve Society--first revision, 2010).

A ausência de comprometimento de nervos cranianos é considerada critério de suporte para o diagnóstico de NMM. Apesar disso, já foram referidos casos com comprometimento dos nervos abducente e hipoglosso (Kaji, Shibasaki e Kimura, 1992; Pringle et al., 1997; Galassi et al., 2012). Os déficits de nervos cranianos podem ser correlacionados com a NMM quando o comprometimento estabiliza ou apresenta recaída em associação com outros déficits da NMM. A fraqueza da musculatura respiratória é extremamente rara na NMM, mas o comprometimento do nervo frênico também já foi descrito (Beydoun e Copeland, 2000; Kyriakides et al., 2011).

Durante a evolução da NMM não são esperados sinais de acometimento do neurônio motor superior, bulbar, déficit sensitivo marcante e fraqueza muscular simétrica nas primeiras semanas de evolução (vide tabela 3). Nesses casos, outros diagnósticos devem ser aventados.

Tabela 3. Critérios de exclusão do diagnóstico clínico.

1- Sinais de acometimento de neurônio motor superior.

2- Comprometimento bulbar marcante.

3- Déficit sensitivo mais marcante que a redução palestésica distal em membros inferiores.

4- Fraqueza simétrica difusa nas primeiras semanas de evolução.

Fonte: Critérios Diagnósticos Clínicos (European Federation of Neurological Societies/Peripheral Nerve Society guideline on management of multifocal motor neuropathy. Report of a joint task force of the European Federation of Neurological Societies and the Peripheral Nerve Society--first revision, 2010). 


\subsection{Características laboratoriais}

Os exames de rotina do sangue e da urina realizados para o diagnóstico da NMM geralmente são normais, exceto pelo achado de níveis ligeiramente elevados de creatinofosfoquinase (CPK) em até dois terços do pacientes (Nobile-Orazio, 2001). Tal fato poderia ser considerado um dos efeitos da desnervação. A análise do líquido cefalorraquidiano (LCR), em aproximadamente 30\% dos pacientes, pode evidenciar discretos aumentos dos níveis de proteína $(<1 \mathrm{~g} / 1)$. Nos demais pacientes o LCR é normal, com ausência de bandas oligoclonais (Nobile-Orazio, 2001). A eletroforese de proteínas séricas é normal na maioria dos pacientes. Em alguns casos, uma proteína monoclonal IgM pode ser detectada (Vlam et al., 2012).

Os anticorpos IgM anti-GM1 são encontrados em aproximadamente 60\% dos pacientes com NMM. A ausência desse anticorpo não é considerada critério de exclusão para o diagnóstico. O seu achado não é suficiente para o diagnóstico. Baixos títulos de IgM anti-GM1 podem ser encontrados na PIDC e ELA. A dosagem de anticorpos torna-se mais útil em pacientes com formas de apresentação atípica, tais como mononeuropatia ou ausência de BC. Em tais casos, um título significativamente elevado de anticorpos anti-GM1 oferece evidência adicional para o diagnóstico de NMM (Muley e Parry, 2012). A titulação de anti-GM1 para seguimento e avaliação da resposta ao tratamento não é útil. Tal fato ocorre porque o tratamento com IgIV pode resultar em melhora clínica, sem alteração dos títulos (Muley e Parry, 2012).

\subsection{Características eletrofisiológicas}

A principal característica da NMM é a presença de $\mathrm{BC}$ em nervos motores fora dos sítios habituais de compressão. No entanto, há formas típicas de NMM que não têm $\mathrm{BC}$ detectável. Tal fato ocorre provavelmente porque esses bloqueios são dependentes de atividade ou estão localizados em segmentos que não são avaliáveis no exame eletrofisiológico de rotina (Delmont et al., 2006). Outras técnicas menos disponíveis, como a estimulação magnética transcraniana, a tripla-estimulação e a estimulação transcutânea da raiz cervical foram utilizadas para identificar BC proximais(Attarian et al., 2005; Deroide et al., 2007). 
Os primeiros artigos definiam BC como uma redução de $20-30 \%$ da amplitude ou da área, se a duração do PAMC distal não excedesse $15 \%$ do normal. Modelos computacionais de $\mathrm{BC}$ e dispersão temporal em animais de experimentação evidenciaram que 50\% de redução da área do PAMC proximal em relação ao distal pode se dever exclusivamente ao cancelamento de fases (Rhee, England e Sumner, 1990). Estudos semelhantes no homem demonstraram que a duração do PAMC distal e o prolongamento da duração do PAMC proximal são fatores importantes para a definição de BC, considerando-se um segmento do nervo mediano ao longo do antebraço. Menor a duração do PAMC distal e menor prolongamento da duração do proximal, menor redução da amplitude é suficiente para diagnosticar um BC (Van Asseldonk, Van Den Berg, Wieneke, et al., 2006).

No novo consenso, a classificação de BC foi modificada e fixada como definido ou provável (Tabela 4).

Tabela 4. Critérios de diagnósticos eletrofisiológicos para bloqueio de condução.

\section{1- Bloqueio de condução motor definido}

Redução da área do pico negativo do PAMC na estimulação proximal x distal de pelo menos 50\% em qualquer segmento do nervo (mediano, ulnar e peroneiro). $\mathrm{O}$ pico negativo do PAMC durante a estimulação do segmento com BC motor deve ser $>20 \%$ do limite inferior da normalidade e $>1 \mathrm{mV}$ e o aumento da duração deve ser $\leq 30 \%$.

\section{2- Bloqueio de condução provável}

Redução da área de pico negativo do PAMC de ao menos 30\% ao longo de um longo segmento (ex: punho ao cotovelo ou do cotovelo à axila) de um nervo no membro superior com um aumento da duração $\leq 30 \%$.

OU

Redução da área de pico negativo do PAMC de ao menos 50\% (semelhante ao BC definido), com um aumento da duração $>30 \%$.

3- Condução nervosa sensitiva normal em segmentos dos membros superiores com bloqueio de condução (ver critérios de exclusão).

**A evidência do BC deve ser encontrada fora de sítios de compressão.

Fonte: Critérios Diagnósticos Eletrofisiológicos para Bloqueio de Condução (European Federation of Neurological Societies/Peripheral Nerve Society guideline on management of multifocal motor neuropathy. Report of a joint task force of the European Federation of Neurological Societies and the Peripheral Nerve Society--first revision, 2010)

Além do BC, outras alterações eletrofisiológicas sinalizando desmielinização focal podem ser evidenciadas. Tais alterações são o prolongamento das latências motoras distais, 
das ondas F ou a sua ausência. Adicionalmente, incluem-se redução da velocidade de condução do PAMC e dispersão temporal (Guimaraes-Costa, Bombelli e Leger, 2013). A eletromiografia pode registrar fasciculações e potenciais de fibrilação, geralmente detectados em territórios com amiotrofia acentuada. Tais achados são consistente com a presença de significativa degeneração axonal (Daube, 2000)

\subsection{Categorias diagnósticas}

O diagnóstico de MMN é baseado em características clínicas, laboratoriais e eletrofisiológicas que já foram citadas anteriormente. Diferentes critérios diagnósticos foram propostos anteriormente (Van Den Berg-Vos, Franssen, et al., 2000) (Olney et al., 2003). A partir da diretriz de 2012, foram definidas as seguintes categorias de critério diagnóstico (tabela 6).

Tabela 6. Categorias diagnósticas.

\section{NMM definida:}

Critérios clínicos 1,2 e 8-10 e critérios eletrofisiológicos 1 e 3 em um nervo.

NMM provável:

Critérios clínicos 1,2 e 8-10 e critérios eletrofisiológicos 2 e 3 em dois nervos.

Critérios clínicos 1,2 e 8-10 e critérios eletrofisiológicos 2 e 3 em um nervo e ao menos dois critérios de suporte da doença.

NMM possível:

Critérios clínicos 1,2 e 8-10 e condução sensitiva normal e critério de suporte $n^{\circ} 4$.

Critério clínico 1 com sinais clínicos presentes em apenas um nervo, critério clínico 2 e 8-11 e critério clínico eletrofisiológico 1,2 1e 3 em um nervo.

Fonte: Categorias Diagnósticas (European Federation of Neurological Societies/Peripheral Nerve Society guideline on management of multifocal motor neuropathy. Report of a joint task force of the European Federation of Neurological Societies and the Peripheral Nerve Society--first revision, 2010). 


\subsection{Comorbidades}

Recentemente algumas doenças autoimunes foram associadas à NMM, tais como a doença celíaca e a tireoidite de Hashimoto (Cats et al., 2012). Alguns parentes de primeiro grau de pacientes com NMM também apresentam uma maior incidência de diabetes tipo 1, doença celíaca e tireoidite de Hashimoto. Tais associações podem indicar um mecanismo patogênico comum e destacam a importância da busca de possíveis comorbidades associadas.

A NMM tem sido referida em pacientes com linfoma de células B e em pacientes que receberam a terapia com Infliximab, reforçando o papel de mecanismos autoimunes no desencadeamento da NMM (Stern et al., 2006; Muley e Parry, 2012; Fernandez-Menendez et al., 2015; Rowan, Tubridy e Cullen, 2015).

\subsection{Diagnóstico diferencial}

Fraqueza muscular assimétrica em grupos musculares distais raramente é encontrada em neuropatias periféricas, sendo compatível com as fases iniciais da doença do neurônio motor (DNM). A NMM pode mimetizar os sintomas iniciais da ELA. Tal ocorre principalmente quando fraqueza muscular e fasciculações ocorrem em concomitância com reflexos vivos no membro afetado. Reflexos indicativos de comprometimento piramidal excluem NMM. A progressão lenta, a ausência de sinais bulbares e a ausência de fraqueza dos músculos respiratórios são de ajuda no diagnóstico diferencial entre NMM e ELA (Vlam et al., 2012).

A distinção da NMM da doença do neurônio motor inferior, particularmente a amiotrofia espinhal distal, pode representar um desafio maior (Visser et al., 2002). O BC pode estar presente em nervos que nem sempre são rotineiramente investigados ou em segmentos de nervos proximais. O achado de hipersinal nas imagens de RM do plexo braquial ponderadas em T2 e a presença de elevados títulos de anticorpos IgM anti-GM1 podem auxiliar no diagnóstico da NMM (Van Den Berg-Vos, Franssen, et al., 2000).

Na presença de BC, a NMM deve ser diferenciada das variantes assimétricas da PIDC. Os pacientes com PIDC apresentam fraqueza distal e proximal simétrica com déficit sensitivo nos membros superiores e inferiores (Van Den Bergh et al., 2010). Contudo, a PIDC também 
pode se apresentar com sinais predominantemente motores e com sintomas sensitivos assimétricos ou multifocais, caracterizando a síndrome de Lewis-Sumner. Quando tais fatos ocorrem, pode ser mais difícil de distingui-las da NMM (Parry, 1999; Van Den Berg-Vos, Van Den Berg, et al., 2000). A fraqueza proximal dos membros inferiores no início do quadro clínico ajuda a diferenciar as variantes motoras puras de PIDC da NMM.

A diferenciação da SLS da NMM pode ser complicada pelo achado de hipopalestesia discreta na NMM. Essa alteração ocorre em cerca de um quinto dos pacientes com NMM (Cats, Van Der Pol, et al., 2010). A distinção entre as duas doenças é extremamente importante. Os pacientes com SLS podem responder ao tratamento com corticosteroides e plasmaférese. Tais alternativas terapêuticas podem agravar a fraqueza muscular em pacientes com NMM (Nobile-Orazio, Cappellari e Priori, 2005). Um curso remitente-recorrente, a progressão dos sintomas em semanas e a ocorrência de déficits sensitivos evidentes e confirmados pela redução da amplitude dos potenciais sensitivos (PAS) são características mais compatíveis com SLS. Outras investigações auxiliares são menos úteis na diferenciação entre as duas doenças. Na maioria dos casos de SLS e NMM, o LCR, ao contrário do que ocorre na PIDC, apresenta níveis normais ou discretamente aumentados de proteína $(<1 \mathrm{~g} / 1)$. A presença de títulos elevados de anticorpos anti-GM1 específicos poderia sugerir NMM, não exclui a SLS (Verschueren et al., 2005).

A neuropatia hereditária com susceptibilidade a compressão pode ser distinguida da NMM com relativa facilidade pelas anormalidades da condução nervosa em sítios de compressão. (Beydoun, 1998).

\subsection{Neuroimagem}

O papel dos exames de imagem na NMM é limitado. Alguns pacientes com NMM podem apresentar um espessamento dos nervos periféricos, particularmente do plexo braquial (Van Es et al., 1997). As alterações na RM incluem hipersinal no plexo braquial e ramos ventrais das raízes nas imagens ponderadas em T2. Tal achado corresponde à distribuição dos sintomas e está associado com edema difuso do nervo (Echaniz-Laguna e Dietemann, 2011). O espessamento de nervos periféricos podem também ser observados em pacientes com PIDC, mas na NMM tendem a ser assimétricos e se localizarem em sítios de BC. 
A investigação ultrassonográfica dos nervos periféricos evidencia espessamentos nervosos generalizados mesmo em segmentos nervosos nos quais não haja $\mathrm{BC}$ (Beekman et al., 2005). Exames de imagem podem ser úteis para o diagnóstico de NMM em casos atípicos e/ou de diagnóstico duvidoso (Muley e Parry, 2012).

\subsection{Biópsia de nervo}

Embora a base patológica do BC seja considerada a desmielinização focal, esta raramente tem sido confirmada na NMM histopatologicamente. Isso ocorre porque a maioria dos pacientes referidos em tais estudos foi submetida à biópsia do nervo sural (Corse et al., 1996). Os resultados de tais estudos foram normais, evidenciaram degeneração axonal discreta ou desmielinização. São condizentes com a baixa frequência e intensidade do comprometimento sensitivo na NMM.

Por outro lado, nos poucos pacientes em que uma biópsia de nervo motor ou mista foi realizada adjacente ao local do $\mathrm{BC}$, foi encontrada a presença de desmielinização com a formação de bulbos de cebola sem infiltrado inflamatório (Kaji et al., 1993). Em outro estudo (Taylor et al., 2004) foi observado um grau variável de degeneração das fibras e brotamentos axonais. Neste estudo não foi observada desmielinização segmentar proeminente ou formações em bulbo de cebola. Tais achados reforçam a hipótese de que o $\mathrm{BC}$ seja secundário a um ataque mediado por anticorpos dirigidos contra componentes do axolema nos nós de Ranvier. Dessa forma, a desmielinização paranodal transitória seria responsável pelo BC.

\subsection{Tratamento}

As opções terapêuticas para a NMM são limitadas (Vlam et al., 2012). Ao contrário dos pacientes com outras neuropatias inflamatórias, os indivíduos com NMM não respondem aos corticosteróides ou à plasmaférese e podem piorar os sintomas motores com esses tratamentos (Carpo et al., 1998). 


\subsubsection{Imunoglobulina endovenosa}

O tratamento imunomodulador com imunoglobulina humana endovenosa (IgIV) em altas doses é atualmente a única intervenção segura e eficaz para pacientes com NMM (Meuth e Kleinschnitz, 2010; Vlam et al., 2012). O objetivo do tratamento com IgIV em pacientes com NMM é de reduzir a incapacidade. Isso é alcançado a partir da reversão do $\mathrm{BC}$ e da prevenção da lesão axonal secundária (Van Asseldonk, Van Den Berg, Kalmijn, et al., 2006; Karam, 2011). O retardo do tratamento com IgIV pode resultar em comprometimento funcional irreversível.

O uso da IgIV como terapia de primeira linha foi baseada inicialmente em uma metaanálise com quatro ensaios clínicos randomizados duplo-cegos, controlados por placebo, envolvendo um total de 34 pacientes (Azulay et al., 1994; Van Den Berg et al., 1995; Federico et al., 2000; Leger et al., 2001). Setenta e oito por cento destes pacientes apresentaram uma significativa melhora da força muscular em prazo curto de tempo após o tratamento com IgIV, quando comparados a $4 \%$ dos pacientes que usaram placebo (Van Schaik et al., 2005).

Os mecanismos de ação da IgIV não são claramente compreendidos. A IgIV: neutraliza anticorpos patogênicos; inibe a produção de anticorpos pelas células B; acelera catabolismo de anticorpos; suprime mediadores pró-inflamatórios produzidos por células T; inibe a inflamação e o dano mediada pelo complemento; induz o bloqueio dos receptores de Fc em macrófagos e regula a proliferação e adesão das células T (Dalakas, 2002) (Yuki et al., 2011).

Recomenda-se uma dose inicial de $2 \mathrm{~g} / \mathrm{kg}$ administrada durante 2-5 dias consecutivos, seguida por uma dose de manutenção de $1 \mathrm{~g} / \mathrm{kg}$ a cada 2-4 semanas ou $2 \mathrm{~g} / \mathrm{kg}$ a cada $1-2$ meses (European Federation of Neurological Societies/Peripheral Nerve Society guideline on management of multifocal motor neuropathy. Report of a joint task force of the European Federation of Neurological Societies and the Peripheral Nerve Society--first revision, 2010).

Embora a terapia com IgIV seja efetiva em quase todos os pacientes com NMM, o tratamento não impede que ocorra um declínio gradual da força muscular ao longo do tempo. Alguns estudos têm avaliado essa questão nos últimos anos. Em um dos tais estudos (Van Den Berg-Vos et al., 2002), realizou-se um seguimento de longo prazo de 11 pacientes com NMM. Esses pacientes foram tratados inicialmente com um curso completo de $\operatorname{IgIV~}(2 \mathrm{~g} / \mathrm{kg})$, seguido por terapia de manutenção variando a partir de uma infusão a cada 1-7 semanas. Durante o período de acompanhamento de 4-8 anos, concluiu-se que a manutenção da terapia 
com IgIV teve um efeito benéfico a longo prazo sobre a força muscular e a incapacidade dos membros superiores. Entretanto, a manutenção pode não evitar uma discreta redução da força muscular. Os achados eletrofisiológicos documentam que o tratamento com IgIV influencia favoravelmente os mecanismos de remielinização ou reinervação, mas que a perda axonal não pode ser evitada. Em outro estudo (Terenghi et al., 2004) realizou-se o seguimento de dez pacientes com NMM que responderam a um curso inicial de IgIV. Foi realizada infusão periódica por 5-12 anos (média de 8,2 anos). Na última avaliação, apenas dois pacientes apresentavam manutenção da melhora máxima conseguida durante a terapia. Outros oito pacientes pioraram mesmo com uso da medicação. Esse declínio começou após 3-7 anos (média 4,8 anos) de terapia e foi correlacionado com redução amplitudes de PAMC distais. Um terceiro estudo (Vucic et al., 2004) documentou uma melhora significativa e sustentada na força muscular e das incapacidades funcionais. Do ponto de vista eletrofisiológico, houve reversão de $\mathrm{BC}$ e nos sinais eletrofisiológicos indicativos de degeneração axonal. Esse estudo fez o seguimento de 10 pacientes com NMM durante 3.5-12 anos (média de 7,25 anos). A diferença entre os resultados pode ser explicada pelos diferentes regimes de IgIV. Os pacientes do último estudo foram tratados com doses de manutenção mais elevadas que os pacientes dos estudos anteriores (Leger, Guimaraes-Costa e Iancu Ferfoglia, 2015).

Em geral a IgIV é segura e bem tolerada. A maioria dos eventos adversos que ocorre em cerca de $5 \%$ do pacientes é de pequena monta. Podem ser associados à infusão de qualquer material biológico. Incluem: dor de cabeça; fadiga; febre; arrepios; hipertensão; erupção cutânea; náusea; astenia e reações locais no sítio da infusão (Eftimov e Van Schaik, 2011) (Stangel et al., 2003). Muitos desses sintomas são controlados ao se retardar a velocidade de infusão em um paciente bem hidratado. Outros eventos adversos mais graves são raramente referidos. Incluem: eventos tromboembólicos; insuficiência renal; reações de hipersensibilidade graves; meningite asséptica; edema pulmonar não cardiogênico e anemia hemolítica. Em pacientes neurológicos, considerando a idade e a doença subjacente, que podem levar a um estilo de vida sedentário, os potenciais fatores de risco devem ser ativamente investigados durante a anamnese e o exame físico (Koski, 2014).

Os eventos tromboembólicos constituem uma complicação rara da IgIV, apresentando uma incidência estimada de 1,7\% com base em estudos prospectivos com pacientes neurológicos. Ocorrem mais frequentemente em indivíduos com múltiplos fatores de risco cardiovasculares (Stangel et al., 2003; Wittstock, Benecke e Zettl, 2003). Em pacientes com risco aumentado de eventos tromboembólicos, medidas antitrombogênicas devem ser consideradas. Deve-se adotar uma menor velocidade na infusão. A dose pode ser dividida em 
vários dias. A formulação deve ser segura. (Koski, 2014). Monitoramento cuidadoso é necessário, particularmente durante a perfusão inicial. Esta pode ser associada com uma maior taxa de complicações, comparada à dos tratamentos posteriores.

\subsubsection{Imunoglobulina subcutânea}

O uso de imunoglobulina por via subcutâneo foi desenvolvido com a intenção de atenuar efeitos colaterais e evitar eventuais dificuldades de acesso venoso. Essa pode ser uma alternativa em termos de eficácia e qualidade de vida dos pacientes. Estudo randomizado realizado em nove pacientes com NMM, responsivos à IgIV (Harbo et al., 2009), a força de músculos afetados e a qualidade de vida em pacientes em uso de IgIV e IgSC foi avaliada. As duas terapias foram igualmente eficazes na média da melhora da força muscular após a infusão: 3,6\% na infusão subcutânea, contra 4,3\% na endovenosa. Um paciente apresentou eritema e edema sustentado nos sítios subcutâneos de infusão durante algumas semanas. Outros pacientes presentaram prurido, eritema, edema e rash com a IgSC. Esses efeitos foram rápidos e passageiros. Após o estudo, cinco dos nove pacientes decidiram manter o tratamento com a infusão subcutânea.

Alguns pacientes com NMM podem responder parcialmente à IgIV. Para outros são necessárias doses progressivamente mais freqüentes para a remissão. Alguns apresentam novos déficits motores, mesmo com periodicidade de infusões mais curtas. Para esses há necessidade de terapias alternativas ou adjuvantes. (Leger, Guimaraes-Costa e Iancu Ferfoglia, 2015).

\subsubsection{Outras terapias}

A ciclofosfamida e o micofenolato de mofetila têm sido as terapias mais frequentemente usadas. Estudos não controlados sugeriram a eficácia da ciclofosfamida. No entanto, as diretrizes de 2010 da European Federation of Neurological Societies/Peripheral Nerve Society consideraram a ciclofosfamida uma opção terapêutica menos desejável devido à sua toxicidade e à falta de estudos controlados. Um estudo (Meucci et al., 1997) mostrou que 
a diminuição da frequência de infusões IgIV foi possível em seis pacientes após a introdução de ciclofosfamida oral como terapia adjuvante. Três outros pacientes apresentaram efeitos colaterais que impediram a continuidade do uso. Tais efeitos foram cistite hemorrágica e amenorréia persistente.

Estudo randomizado, duplo cego e controlado por placebo (Piepers et al., 2007), avaliou o uso do micofenolato de mofetila $1 \mathrm{~g}$ duas vezes por dia, em 28 pacientes com NMM, por um ano. Não houve redução significativa da dose de IgIV, ou alteração da força muscular e nos escores funcionais entre ambos os grupos.

Estudos experimentais indicam que a patogenicidade é complemento-mediada de anticorpos anti-GM1. O anticorpo monoclonal eculizumab se liga ao fator C5 do sistema complemento e o neutraliza. Isto previne a ativação da cascata do complemento e a lise da membrana através do CAM. A sua segurança e eficácia foram comprovadas em outras doenças complemento-mediadas, tais como na hemoglobinúria paroxística noturna (Hillmen et al., 2006). Um estudo clínico não randomizado foi realizado em 13 pacientes com NMM em uso de eculizumab por 14 semanas, 10 dos quais em associação com IgIV (Fitzpatrick et al., 2011). Os resultados revelaram uma tendência de melhora em escalas subjetivas e aumento da força muscular avaliada por dinamômetro. Na avaliação eletrofisiológica houve uma pequena, mas significativa diminuição do percentual de BC nos nervos estudados.

Outros estudos não controlados sugeriram efeitos benéficos do tratamento com o interferon- $\beta$, ciclosporina, metotrexato e azatioprina em alguns pacientes com NMM (Nemni et al., 2003; Eftimov e Van Schaik, 2011), todos com resultados pouco promissores. Vários estudos de caso têm indicado a eficácia do uso do Rituximab, um anticorpo monoclonal dirigido contra o antígeno de células B CD20. Os resultados são ainda considerados inconsistentes (Vlam et al., 2012). Ensaios clínicos duplo-cegos, controlados e aleatórios são necessários para verificar a sua segurança e eficácia no tratamento dos pacientes com NMM.

\subsection{Prognóstico}

O curso da doença é geralmente lento e progressivo (Cats, Jacobs, et al., 2010). Raros casos de remissão espontânea foram descritos (Nobile-Orazio, 2001). Os pacientes com NMM em geral não desenvolvem fraqueza bulbar e insuficiência respiratória, apresentando uma expectativa de vida normal. 
Apesar dos efeitos benéficos do tratamento com IgIV, a maioria dos pacientes apresenta um declínio lentamente progressivo da força muscular, evoluindo para uma incapacidade considerável (Terenghi et al., 2004) (Van Den Berg-Vos et al., 2002). O comprometimento funcional grave dos MMSS é referido por $20 \%$ dos pacientes. Severa fadiga, que interfere nas atividades da vida profissional ou diária, é referenciada por mais da metade dos pacientes (Cats, Jacobs, et al., 2010). A fraqueza e a incapacidade permanentes são determinadas pelo número de anos sem tratamento e pela intensidade da perda axonal (Van Asseldonk, Van Den Berg, Kalmijn, et al., 2006). O reconhecimento precoce e o tratamento adequado da NMM são de grande importância. As estratégias futuras de tratamento devem objetivar a atenuação da perda axonal (Vlam et al., 2012).

\subsection{Avaliação das incapacidades}

Há diferentes escalas para a avaliação do déficit motor e incapacidade em pacientes com NMM. Não há um consenso quanto ao desfecho primário, tanto em ensaios clínicos, como na prática clínica. Uma escala foi recentemente delineada a partir dos resultados do Estudo PeriNoms (PNS), que foi realizado entre 2007 e 2012, (Vanhoutte et al., 2012). A partir disso, a escala $M M N-R O D S$ foi construída. Trata-se de uma escala construída especificamente para identificar limitações de atividades em pacientes com NMM, com base no método Rasch. Trata-se de ferramenta obrigatória em futuros estudos de graduação de déficits e verificação da eficácia de tratamento. 


\section{JUSTIFICATIVA}

A Neuropatia Motora Multifocal é uma doença de diagnóstico difícil e com apresentação clínica e eletrofisiológica não habitual. Diante de sua baixa incidência, poucos estudos estão disponíveis na literatura sobre a doença. Não há nenhum relato sobre as características da doença e seu prognóstico em pacientes brasileiros. Diante da incapacidade gerada pela doença e da falta de tratamentos eficazes alternativos à infusão periódica de imunoglobulina humana, novos estudos podem proporcionar uma maior compreensão da doença, ampliando as possibilidades terapêuticas. 


\section{OBJETIVOS}

\subsection{Objetivos gerais}

O objetivo do presente estudo é verificar a evolução, as características clíniconeurológicas da NMM em pacientes em seguimento no Hospital das Clínicas de Ribeirão Preto. 


\section{MATERIAIS E MÉTODOS}

\subsection{Desenho do estudo}

Trata-se de um estudo observacional, descritivo e retrospectivo de um grupo de pacientes com neuropatia motora multifocal em seguimento no Hospital das Clínicas de Ribeirão Preto.

\subsection{Pacientes}

Foram analisados os dados de pacientes em seguimento no ambulatório de doenças neuromusculares, a partir de Janeiro de 1990 até o mês de novembro de 2015, que receberam o diagnóstico clínico e eletrofisiológico de Neuropatia Motora Multifocal.

Os pacientes foram recrutados a partir da busca ativa da pesquisadora nos bancos de dados do setor de neurofisiologia, nas listas de pacientes em tratamento e dos pacientes em seguimento ambulatorial. Os prontuários destes pacientes foram revisados de maneira sistemática.

\subsection{Critérios de inclusão}

Foram recrutados os pacientes com diagnóstico de Neuropatia Motora Multifocal de acordo com os mais recentes critérios diagnósticos da European Federation of the Neurological Societies e Peripheral Nerve Society (Joint Task Force of the EFNS and the PNS, 2010. 


\subsubsection{Critérios clínicos}

Foram incluídos os pacientes que apresentaram fraqueza lentamente progressiva, com períodos de estabilização, focal, assimétrica, com mais de um mês de evolução e pacientes com ausência de anormalidades sensitivas objetivas, sendo tolerada apenas a presença de hipopalestesia distal em membros inferiores.

\subsubsection{Critérios eletrofisiológicos}

Os estudos de condução nervosa e eletromiografia dos pacientes foram coletados retrospectivamente. Os exames foram realizados no setor de Neurofisiologia/Eletroneuromiografia do HC-FMRP, nos aparelhos MEB 4200K e MEB 7200K (NIHON-KOHDEN). Os filtros de frequência utilizados foram de 10 a $10.000 \mathrm{~Hz}$ para a condução sensitiva e de 2 a $10.000 \mathrm{~Hz}$ para a condução motora. $\mathrm{O}$ estímulo foi realizado por pulsos retangulares com duração de $0,2 \mathrm{~ms}$, chegando-se até $1 \mathrm{~ms}$ de acordo com o limiar de excitabilidade do nervo avaliado. A intensidade do estímulo foi ajustada de forma a se obter uma resposta supramáxima dos nervos estudados, chegando-se a um limite de intensidade da corrente de $100 \mathrm{~mA}$ para a condução motora e $50 \mathrm{~mA}$ para a condução sensitiva.

Foram recrutados os pacientes que apresentavam o bloqueio de condução definido ou o bloqueio de condução parcial, com a condução sensitiva normal em segmentos do membro superior com o bloqueio de condução, respeitando os critérios diagnósticos da European Federation of the Neurological Societies e Peripheral Nerve Society (Joint Task Force of the EFNS and the PNS, 2010.

Os pacientes que não apresentavam o bloqueio de condução, porém que apresentavam um padrão de acometimento nervo a nervo no exame de agulha, com ausência de alterações sensitivas e com boa resposta à infusão de Imunoglobulina também foram incluídos no estudo.

Foram incluídos ainda os pacientes que apresentavam o bloqueio de condução pelo método de ressíntese. Neste método desenvolvido pelo Prof. Dr. Wilson Marques Júnior e Dr. Austin J. Sumner, ainda não publicado, busca demonstrar a presença de possíveis bloqueios de condução proximais. Nesta avaliação testa-se a condução motora durante a estimulação 
elétrica e solicita-se que paciente realize uma contração voluntária, comparando-se as unidades motoras recrutadas por ambos os métodos. A ausência ou a redução de unidades motora recrutadas voluntariamente comparada com a estimulação elétrica caracteriza um bloqueio de condução provável.

\subsection{Critérios de não inclusão}

Não foram incluídos os indivíduos que preenchiam critérios de exclusão para o diagnóstico da NMM de acordo com os critérios diagnósticos da European Federation of the Neurological Societies e Peripheral Nerve Society (Joint Task Force of the EFNS and the PNS, 2010). Foram excluídos os pacientes que apresentavam sinais de comprometimento do neurônio motor superior, pacientes com comprometimento bulbar marcante, pacientes com déficit sensitivo mais marcante que a redução palestésica distal em membros inferiores e pacientes com início do quadro com fraqueza simétrica difusa nas primeiras semanas de evolução.

\subsection{Caracterização fenotípica}

Todos os indivíduos com diagnóstico de NMM foram atendidos no Hospital das Clínicas da Faculdade de Medicina de Ribeirão Preto, apresentando no prontuário médico anamnese e exame neurológico pormenorizado pela equipe de neurologia/neuromuscular do hospital e realização do exame da condução nervosa e eletromiografia. As informações clínicas coletadas e consideradas na análise foram as seguintes:
a) Idade do início dos sintomas;
b) Sexo;
c) Manifestação clínica inicial;
d) Comorbidades;
e) Tempo de doença;
f) Presença de sintomas sensitivos;
g) Graduação dos reflexos no membro afetado; 
h) Tempo do início dos sintomas ao tratamento;

i) Diagnóstico inicial;

j) Presença de hiperproteinorraquia no líquor;

1) Positividade do anticorpo anti-GM1;

m) Nervos afetados;

n) Presença de bloqueio de condução;

o) Topografia do bloqueio de condução;

p) Resposta à imunoglobulina;

q) Uso de outras medicações imunossupressoras;

A manifestação clínica inicial foi considerada como o primeiro sintoma a ser notado e relatado pelo paciente, sendo classificado de acordo com seu sítio de início. Os dados de exame físico do paciente foram coletados na primeira ficha de atendimento. Os reflexos foram graduados em: hiperreflexia, vivos, normais, hiporreflexos e arreflexos, de acordo com o seu limiar de resposta, amplitude de resposta, velocidade da resposta, presença de resposta contralateral, área provocadora do reflexo, presença de resposta policinético, resposta invertida ou presença de reflexo pendular.

A distribuição do bloqueio de condução foi classificada de acordo com o nervo acometido pelo bloqueio e sua topografia, ex: Erb-axila, proximal, distal. Outras características, tais como redução da amplitude do PAMC e outros sinais de desmielinização focal também foram analisados.

O diagnóstico inicial do paciente refere-se ao primeiro diagnóstico clínico recebido pelo paciente, tanto nesta como em outras instituições de origem. O diagnóstico inicial foi coletado tanto a partir de fichas de encaminhamento, como a partir do relato do próprio paciente.

Diante da ausência de uma escala de incapacidade uniformizada, a resposta a IgIV foi considerada insatisfatória, quando havia uma queixa de piora subjetiva pelo paciente, uma perda objetiva na realização de atividades da vida diária, uma piora objetiva no exame físico ou quando era determinada a troca da medicação pela equipe médica durante avaliação ambulatorial. 


\subsection{Análise laboratorial}

Dos vinte de nove pacientes, oito foram puncionados para a realização de bioquímica e celularidade do LCR. Todos os pacientes foram puncionados nesta instituição. Analisou-se a presença de hiperproteinorraquia no líquor, com limite de corte maior que $44 \mathrm{mg} / \mathrm{dl}$ para hiperproteinorraquia na punção lombar.

Além do LCR, outros onze pacientes tiveram coleta de sangue para a realização de análise sorológica para a pesquisa do anticorpo anti-GM1. Todas as amostras foram realizadas em laboratórios externos e alguns resultados não trouxeram o título sérico dos pacientes positivos, sendo analisado apenas a presença ou ausência deste anticorpo.

\subsection{Análise estatística}

Foram realizadas as análises descritivas do grupo de pacientes com NMM. Posteriormente, realizou-se uma análise descritiva com porcentagens de eventos. A análise estatística foi realizada com o auxílio do software SPSS Statistics versão 17.0.

\subsection{Aprovação pelo Comitê de Ética}

O trabalho foi aprovado pela Comissão de Ética e Pesquisa do Hospital das Clínicas de Ribeirão Preto (processo HC-FMRP no: 1.409.713). 


\section{RESULTADOS}

\subsection{Análise descritiva da população estudada}

Vinte e nove pacientes com NMM foram identificados. As características demográficas destes pacientes encontram-se na tabela 7 .

Tabela 7. Características demográficas dos pacientes com NMM.

\begin{tabular}{cc}
\hline Características & Valores \\
\hline Sexo masculino & $18(62 \%)$ \\
Idade de início dos sintomas & 42,7 anos $(12-80)$ \\
Homens & 42,7 anos $(17-71)$ \\
Mulheres & 42,7 anos $(12-80)$ \\
Tempo de duração da doença & 10,2 anos $(0,5-29)$ \\
\hline
\end{tabular}

Dos vinte e nove pacientes avaliados, dezoito pacientes (62\%) eram homens e onze mulheres (38\%). A média de idade de início dos sintomas foi de 42,7 anos (12 a 80 anos), não havendo diferença na média de idade de início dos sintomas entre os sexos. A média de tempo da duração da doença foi de 10,2 anos (0,5 - 29).

\subsection{Características clínicas}

O resumo das características clínicas da população estudada encontra-se na tabela 8. A hipertensão ou diabetes foram as doenças mais comumente associadas à NMM, presentes em oito pacientes $(27,5 \%)$. Um paciente teve o diagnóstico de Síndrome de Sjogren. Oito pacientes $(27,5 \%)$ eram tabagistas ou ex-tabagistas. Nenhum paciente apresentou história familiar da doença. 
O sítio de início dos sintomas foi nos membros superiores em vinte e cinco pacientes $(86,2 \%)$ e nos membros inferiores em quatro pacientes $(13,7 \%)$, todos presentes na musculatura distal dos membros. O início da doença apresentou-se de forma assimétrica em todos os pacientes e três pacientes $(10,3 \%)$ apresentavam queixa sensitiva, relatada como parestesia, que não era objetiva ao exame clínico, nem apresentavam alterações no potencial de ação sensitivo ao exame eletrofisiológico.

A queixa mais comum no início dos sintomas foi o déficit motor para a extensão dos dedos, presente em onze pacientes (37,9\%). Treze pacientes apresentavam reflexos normais $(46,4 \%)$ no membro afetado, treze pacientes apresentaram hiporreflexia ou arreflexia no membro afetado $(46,4 \%)$ e dois pacientes apresentaram reflexos vivos $(7,1 \%)$. A descrição do reflexo tendíneo não estava disponível no prontuário médico de um paciente.

O diagnóstico inicial foi diferente de NMM na maioria dos pacientes $(51,7 \%)$, sendo a DNM o segundo diagnóstico inicial mais frequente nestes pacientes $(20,6 \%)$.

Tabela 8. Características clínicas dos pacientes com NMM.

\begin{tabular}{cc}
\hline Características & Valores \\
\hline Sítio de início dos sintomas & $25(86,2 \%)$ \\
Membros superiores & $4(13,7 \%)$ \\
Membros inferiores & $3(10,3 \%)$ \\
Presença de queixa sensitiva (PAS normal) & \\
Diagnóstico inicial & $14(48,2 \%)$ \\
NMM & $6(20,6 \%)$ \\
DNM & $3(10,3 \%)$ \\
Radiculopatia & $1(3,4 \%)$ \\
Compressão focal & $1(3,4 \%)$ \\
HNPP & $1(3,4 \%)$ \\
Amiotrofia espinhal distal & 4,9 anos $(1-11$ anos $)$ \\
\hline
\end{tabular}

*PAS: Potencial de ação sensitivo 


\subsection{Características laboratoriais}

A amostra de líquido cefalorraquidiano (LCR) foi coletada em oito pacientes, sendo evidenciada hiperproteinorraquia em quatro pacientes $(50 \%)$. O valor mais elevado de proteína no LCR foi de $78,13 \mathrm{mg} / \mathrm{ml}$.

Onze pacientes coletaram soro para a pesquisa do anticorpo anti-GM1 e cinco pacientes $(45,4 \%)$ apresentaram resultados positivos para este anticorpo, todos IgM. A análise laboratorial dos pacientes encontra-se na tabela 9.

Tabela 9. Características laboratoriais dos pacientes com NMM.

\begin{tabular}{lc}
\hline Hiperproteinorraquia * & $4(50 \%)$ \\
Presença anti-GM1 ** & $5 \quad(45,4 \%)$ \\
\hline *Total de 8 pacientes puncionados para a análise do LCR. & \\
$* *$ Total de 11 pacientes com análise sorológica para anti-GM1. &
\end{tabular}

\subsection{Características eletrofisiológicas}

Todos os pacientes realizaram a eletroneuromiografia neste serviço. Dezenove pacientes $(65,3 \%)$ apresentaram alteração eletrofisiológica de até quatro nervos estudados. Um paciente $(3,4 \%)$ apresentou mononeuropatia e outro paciente apresentou doze nervos acometidos durante o exame eletroneuromiográfico.

Doze pacientes apresentaram bloqueio de condução provável ou definido $(44,4 \%)$, onze pacientes não apresentaram bloqueio de condução $(40,7 \%)$ e quatro pacientes $(14,8 \%)$ apresentaram bloqueio de condução pelo método de ressíntese. Dos pacientes que não apresentaram bloqueio de condução, sete pacientes $(24,1 \%)$ apresentaram outros sinais de desmielinização focal, tais como dispersão temporal e redução da velocidade focal em nervos afetados e quatro pacientes $(13,7 \%)$ apresentaram um padrão de comprometimento nervo a nervo na eletroneuromiografia.

O bloqueio de condução foi mais frequentemente encontrado nos nervos ulnares $(42,1 \%)$, seguido pelo nervo mediano $(31,5 \%)$, do nervo radial $(15,7 \%)$ e dos nervos peroneiros e tibiais posteriores (ambos com 5,2\%). O sítio mais comum de detecção do bloqueio de condução foi no 
segmento do braço $(36,3 \%)$, seguido pelo segmento do antebraço $(31,8 \%)$. A estimulação do ponto de Erb definiu o terceiro sítio mais comum de acometimento do bloqueio de condução $(22,7 \%)$, presente em quatro vezes no nervo ulnar e uma vez no radial.

Os achados de desmielinização focal já foram previamente relatados (Cornblath et al., 1991; Katz et al., 1997), sendo também encontrados neste estudo. De todos os pacientes, encontramos que dezenove pacientes $(65,5 \%)$ apresentavam outros sinais de desmielinização, estando presentes a dispersão temporal $(53,8 \%)$, reduções focais da velocidade de condução $(41,6 \%)$ e prolongamento das latências mínimas das ondas $\mathrm{F}(8,3 \%)$.

Apesar da descrição do acometimento sensitivo na NMM (Delmont et al., 2009; Lambrecq et al., 2009), pacientes com comprometimento sensitivo no exame de eletroneuromiografia foram excluídos deste trabalho. Apenas pacientes com queixa de redução da palestesia distal em membros inferiores foram incluídos e não foi analisada uma possível redução do potencial de ação sensitivo no decorrer da doença.

As características eletrofisiológicas da população estudada encontram-se na tabela abaixo.

Tabela 10. Características eletrofisiológicas dos pacientes com NMM.

\section{Número de nervos acometidos}

1

2

3

4

5

$>5$

$>10$

Presença de BC

Distribuição do BC

Ulnar

Mediano

Radial

Peroneiro

Tibial

\section{Topografia do BC}

Proximal (Erb-Axila)

Braço

Antebraço

Perna
$1(3,4 \%)$

$9(31 \%)$

$2(6,8 \%)$

$7(24,1 \%)$

$2(6,8 \%)$

$7(24,1 \%)$

$1(3,4 \%)$

$12(44,4 \%)$

$8(42,1 \%)$

$6(31,5 \%)$

$3(15,7 \%)$

$1(5,2 \%)$

$1(5,2 \%)$

$5(22,7 \%)$

$8(36,3 \%)$

$7(31,8 \%)$

$2(9,0 \%)$ 


\subsection{Características da evolução e do tratamento}

Em geral os pacientes iniciaram o tratamento após 4,9 anos do início dos sintomas. A data de início do tratamento não se encontrava disponível no prontuário em quatro pacientes. Dois pacientes ainda não haviam iniciado tratamento, pois estavam aguardando a medicação.

A análise de regressão da relação do número de nervos acometidos versus o tempo de duração da doença, mostrou uma tendência linear, porém sem significância estatística $(\mathrm{p}=0,113)$.

A avaliação da resposta ao tratamento foi realizada de maneira subjetiva durante os atendimentos contidos no prontuário. A partir do relato da capacidade funcional do paciente e da análise do exame físico de consultas ambulatoriais regulares, a equipe avaliava se a resposta ao tratamento era adequada. De uma forma geral, onze pacientes (50\%) apresentaram uma resposta satisfatória com o uso da IgIV em altas doses. Outros onze pacientes apresentaram uma resposta parcial ou não responderam ao uso da IgIV, sendo indicado pela equipe o uso de outras medicações imunossupressoras. Seis pacientes $(27,2 \%)$ fizeram uso de Ciclofosfamida, quatro pacientes $(18,18 \%)$ fizeram uso de Rituximabe, um paciente fez uso de Azatioprina e outro paciente fez uso de Solumedrol (4,5\%)

Atualmente, nenhum paciente segue em uso de Ciclofosfamida ou Azatioprina e três pacientes seguem em uso de Rituximab, com resposta clínica adequada. Um paciente não obteve melhora ou estabilização dos sintomas motores com o uso de Rituximab. O paciente que fez uso de Solumedrol teve uma melhora dos sintomas nos primeiros dois meses de início da medicação, apresentando nova piora da capacidade funcional durante o uso do corticoide, sendo modificado o esquema terapêutico. 


\section{DISCUSSÃO}

\subsection{Discussão das características demográficas}

Este trabalho recrutou vinte e nove pacientes com diagnóstico de NMM em seguimento no Hospital das Clínicas da Faculdade de Medicina de Ribeirão Preto. Calcula-se, de acordo com os dados de atendimentos deste hospital, uma prevalência da doença de 2,4 pacientes por 100.000 pacientes em atendimentos nesta instituição. Esta prevalência é cerca de quatro vezes maior do que a prevalência relatada na literatura (Cats, Jacobs, et al., 2010). Acreditamos que a nossa elevada prevalência ocorra devido a esta instituição ser referência nos atendimentos em neurologia e, especialmente em neuropatias, recebendo pacientes de todo Brasil para definição diagnóstica e tratamento. Além disso, este estudo recrutou pacientes que preenchiam critérios clínicos, sem a necessidade da presença do BC de condução para a definição da doença (NMM possível e provável). Outros estudos populacionais, anteriores à classificação diagnóstica de 2010, incluíram apenas pacientes que apresentavam BC (NMM definida).

O nosso estudo confirmou que a doença predomina em homens, tal como observado em estudos cuja casuística foi igual ou maior que 30 pacientes (Taylor et al., 2000; Slee, Selvan e Donaghy, 2007; Cats, Jacobs, et al., 2010). A média de idade do início dos sintomas por volta da quarta década de vida confirma o que é referido em estudos anteriores. $\mathrm{O}$ único trabalho na nossa revisão que avaliou a diferença na idade de início dos sintomas entre os sexos, evidenciou que a doença se inicia, em média 7 anos antes nos homens (Cats, Jacobs, et al., 2010). Nossos achados não evidenciaram diferença na idade de início entre homens e mulheres.

Considerando os extremos de idade, encontramos referência à apenas dois pacientes com início prévio aos doze anos de idade. (Moroni et al., 2006; Ramdas et al., 2013). Estes pacientes eram do sexo masculino com início aos seis e aos doze anos de idade. As características da apresentação clínica foram semelhantes às dos pacientes adultos e ambos apresentavam bloqueio de condução. A nossa paciente é do sexo feminino, teve início da doença aos 10 anos de idade, apresentando evolução clínica semelhante aos adultos, entretanto, não apresentava bloqueio de condução no exame eletroneuromiográfico. 
Uma paciente do nosso trabalho teve início dos sintomas aos oitenta anos de idade e um paciente teve início aos 71 anos, não sendo relatado na literatura até o momento início da doença com idade maior que 70 anos (Vlam et al., 2012).

\subsection{Discussão das características clínicas inciais}

A apresentação clínica e o padrão da fraqueza dos pacientes tiveram início distal tanto em membros superiores, quanto em membros inferiores. $\mathrm{O}$ início nos membros inferiores esteve presente em 13,7\% dos pacientes e também foi descrito com percentuais semelhantes em outros estudos (Taylor et al., 2000; Terenghi et al., 2004). Os nervos ulnares, medianos e radiais foram os mais comumente afetados, com padrões de fraqueza diferentes em músculos inervados por um mesmo ramo terminal. Este achado já foi descrito anteriormente em outros estudos (Slee, Selvan e Donaghy, 2007; Cats, Jacobs, et al., 2010) e sugerem um padrão de acometimento desigual (Nobile-Orazio, Cappellari e Priori, 2005).

Neste estudo evidenciou-se uma maior prevalência de reflexos normais nos indivíduos acometidos do que na literatura (Nobile-Orazio, 2001; Cats, Jacobs, et al., 2010). Este achado pode ser explicado diante do fato de que a coleta dos dados do exame físico ter sido realizada no primeiro atendimento do paciente, quando não havia perda axonal, nem perda funcional tão pronunciada. Além disso, nossos pacientes apresentam um tempo médio de duração da doença menor que esses estudos.

\subsection{Discussão das características laboratoriais}

Neste estudo, 45,4\% dos pacientes que coletaram amostra de soro foram positivos para o anticorpo anti-GM1. Outras séries de casos apresentam taxas de positividade de 30-80\% (Kornberg e Pestronk, 1994; Bouche et al., 1995; Delmont et al., 2007), que pode variar conforme o método utilizado.

Os pacientes que apresentaram anticorpos positivos, não diferiram clinicamente, nem eletrofisiologicamente dos pacientes soronegativos. Somente onze pacientes deste estudo realizaram a coleta para a pesquisa do anticorpo, sendo utilizado como um critério laboratorial 
de suporte para NMM. Nós concordamos que este pode ser um exame auxiliar em situações em que um diagnóstico definitivo de NMM não pode ser feito, entretanto não pode ser usado como critério fundamental para o diagnóstico (Taylor, Gross e Windebank, 1996; NobileOrazio, Cappellari e Priori, 2005).

\subsection{Discussão das características eletrofisiológicas}

A eletroneuromiografia é crucial para diferenciar a NMM de outras neuropatias e principalmente da DNM. Como a presença do BC é mais frequente em sítios proximais é fundamental a realização do exame de maneira minuciosa e expandida, realizando-se também o estudo do nervo radial. O exame com agulha deve ser realizado de forma sistemática e pode auxiliar na distinção entre o padrão de acometimento de nervo e raiz. A importância e a relação entre a redução do PAMC e os achados de potenciais neurogênicos dos músculos com a mesma inervação nervosa na NMM já haviam sido previamente relatados (Van Asseldonk, Van Den Berg, Kalmijn, et al., 2006).

\subsection{Discussão das características da evolução e tratamento}

O efeito benéfico da IgIV é bem estabelecido (Federico et al., 2000) (Azulay et al., 1994; Van Den Berg et al., 1995), entretanto vários pacientes deste estudo demonstraram uma resposta parcial ou insatisfatória à infusão desta medicação. Este achado pode ser secundário ao diagnóstico tardio, o que os leva a iniciar a medicação com grande perda funcional e lesão axonal; ao fato de muitas vezes a medicação não estar disponível para infusão periódica; e ao transtorno causado pela necessidade de infusão em ambiente hospitalar, provocando um tratamento irregular e pouco eficaz. Acreditamos que a disponibilização pelo Sistema Único de Saúde da Imunoglobulina subcutânea, poderia amenizar efeitos colaterais e tornar a infusão mais regular.

A partir dos inúmeros efeitos colaterais secundários à administração da ciclofosfamida, o uso do Rituximab tem se tornado uma estratégia de tratamento eficaz nos pacientes desta instituição com falha ao tratamento com IgIV. Conforme já documentado na 
literatura (Donaghy et al., 1994), nosso paciente tratado com corticoide apresentou piora clínica com a infusão da medicação de forma regular.

Diante do desenho seccional do estudo e da ausência de escalas uniformizadas para a avaliação da capacidade funcional dos pacientes com NMM, uma grande limitação deste trabalho é não conseguir analisar possíveis fatores prognósticos da doença e resposta ao tratamento.

Como todo estudo retrospectivo, grande parte da coleta de dados foi realizada através do prontuário médico, sujeita a viés de informação, quando possíveis dados de anamnese e de exames realizados que poderiam não estar disponíveis no prontuário. 


\section{CONCLUSÕES}

A NMM é uma doença rara, com ausência de relatos de suas características clínicas na população brasileira. Na nossa população estudada, as características clínico-neurológicas da NMM parecem se assemelhar a outras casuísticas mundiais.

A doença apresentou maior prevalência em homens, com média de início de idade por volta dos quarenta anos em ambos os sexos. Nesse estudo encontramos dois pacientes com início da doença acima dos 70 anos, fato ainda não relatado na literatura. Tais pacientes apresentaram evolução clínica semelhante aos pacientes mais jovens.

Evidenciou-se o maior comprometimento da força muscular dos membros superiores em $86,3 \%$. Três pacientes apresentavam queixa sensitiva subjetiva, sem alteração no exame eletrofisiológico. A maior parte dos pacientes apresentou reflexos normais no início da avaliação, o que difere dos resultados na literatura. Entretanto, esses reflexos foram avaliados no início do surgimento dos sintomas.

Metade dos pacientes puncionados apresentaram hiperproteinorraquia, com nível máximo de 78,13 mg/ml. Dos pacientes que realizaram coleta sorológica, 45\% apresentaram positividade para o anticorpo anti-GM1.

O sítio mais comum de bloqueio de condução foi no nervo ulnar, seguido do nervo mediano. A topografia mais comum do bloqueio foi no segmento do braço. Outros achados comumente encontrados de desmielinização foram a dispersão temporal e a redução focal da velocidade de condução.

Há uma tendência de relação linear entre o tempo de duração da doença e o número de nervos acometidos, porém sem significância estatística $(p=0,113)$. Comparando-se essa população com outras casuísticas mundiais, nossos pacientes apresentam um declínio da capacidade mais acentuado em relação a outras populações. Este declínio pode estar associado a um diagnóstico tardio, a um atraso para o início do tratamento e ao tratamento irregular. 


\section{REFERÊNCIAS BIBLIOGRÁFICAS}

ATTARIAN, S. et al. Magnetic stimulation using a triple-stimulation technique in patients with multifocal neuropathy without conduction block. Muscle Nerve, v. 32, n. 6, p. 710-4, Dec 2005. ISSN 0148-639X (Print)0148-639x. Disponível em: < http://dx.doi.org/10.1002/ mus. $20434>$.

AZULAY, J. P. et al. Intravenous immunoglobulin treatment in patients with motor neuron syndromes associated with anti-GM1 antibodies: a double-blind, placebo-controlled study. Neurology, v. 44, n. 3 Pt 1, p. 429-32, Mar 1994. ISSN 0028-3878 (Print)0028-3878. Disponível em: < http://dx.doi.org/ >.

BEEKMAN, R. et al. Ultrasonography shows extensive nerve enlargements in multifocal motor neuropathy. Neurology, v. 65, n. 2, p. 305-7, Jul 26 2005. ISSN 0028-3878. Disponível em: < http://dx.doi.org/10.1212/01.wnl.0000169179.67764.30>.

BEYDOUN, S. R. Multifocal motor neuropathy with conduction block misdiagnosed as multiple entrapment neuropathies. Muscle Nerve, v. 21, n. 6, p. 813-5, Jun 1998. ISSN 0148639X (Print)0148-639x. Disponível em: < http://dx.doi.org/ >.

BEYDOUN, S. R.; COPELAND, D. Bilateral phrenic neuropathy as a presenting feature of multifocal motor neuropathy with conduction block. Muscle Nerve, v. 23, n. 4, p. 556-9, Apr 2000. ISSN 0148-639X (Print)0148-639x. Disponível em: < http://dx.doi.org/ >.

BOSTOCK, H.; ROTHWELL, J. C. Latent addition in motor and sensory fibres of human peripheral nerve. J Physiol, v. 498 ( Pt 1), p. 277-94, Jan 1 1997. ISSN 0022-3751 (Print)0022-3751. Disponível em: < http://dx.doi.org/ >.

BOUCHE, P. et al. Multifocal motor neuropathy with conduction block: a study of 24 patients. J Neurol Neurosurg Psychiatry, v. 59, n. 1, p. 38-44, Jul 1995. ISSN 0022-3050 (Print)0022-3050. Disponível em: < http://dx.doi.org/ >.

BURKE, D.; KIERNAN, M. C.; BOSTOCK, H. Excitability of human axons. Clin Neurophysiol, v. 112, n. 9, p. 1575-85, Sep 2001. ISSN 1388-2457 (Print)1388-2457. Disponível em: < http://dx.doi.org/ >.

CARPO, M. et al. Deterioration of multifocal motor neuropathy after plasma exchange. Neurology, v. 50, n. 5, p. 1480-2, May 1998. ISSN 0028-3878 (Print)0028-3878. Disponível em: $<$ http://dx.doi.org/ $>$. 
CATS, E. A. et al. Associated autoimmune diseases in patients with multifocal motor neuropathy and their family members. J Neurol, v. 259, n. 6, p. 1137-41, Jun 2012. ISSN 0340-5354. Disponível em: < http://dx.doi.org/10.1007/s00415-011-6315-3>.

CATS, E. A. et al. Multifocal motor neuropathy: association of anti-GM1 IgM antibodies with clinical features. Neurology, v. 75, n. 22, p. 1961-7, Nov 30 2010. ISSN 0028-3878. Disponível em: < http://dx.doi.org/10.1212/WNL.0b013e3181ff94c2 >.

CATS, E. A. et al. Correlates of outcome and response to IVIg in 88 patients with multifocal motor neuropathy. Neurology, v. 75, n. 9, p. 818-25, Aug 31 2010. ISSN 0028-3878. Disponível em: < http://dx.doi.org/10.1212/WNL.0b013e3181f0738e >.

CHARLES, N. et al. Intravenous immunoglobulin treatment in multifocal motor neuropathy. In: (Ed.). Lancet. England, v.340, 1992. p.182. ISBN 0140-6736 (Print)0140-6736 (Linking).

CORNBLATH, D. R. et al. Conduction block in clinical practice. Muscle Nerve, v. 14, n. 9, p. 869-71; discussion 867-8, Sep 1991. ISSN 0148-639X (Print)0148-639x. Disponível em: < http://dx.doi.org/ >.

CORSE, A. M. et al. Sensory nerve pathology in multifocal motor neuropathy. Ann Neurol, v. 39, n. 3, p. 319-25, Mar 1996. ISSN 0364-5134 (Print)0364-5134. Disponível em: < http://dx.doi.org/10.1002/ana.410390308>.

DALAKAS, M. C. Mechanisms of action of IVIg and therapeutic considerations in the treatment of acute and chronic demyelinating neuropathies. Neurology, v. 59, n. 12 Suppl 6, p. S13-21, Dec 24 2002. ISSN 0028-3878 (Print)0028-3878. Disponível em: < http://dx.doi.org/ >.

DAUBE, J. R. Electrodiagnostic studies in amyotrophic lateral sclerosis and other motor neuron disorders. Muscle Nerve, v. 23, n. 10, p. 1488-502, Oct 2000. ISSN 0148-639X (Print)0148-639x. Disponível em: < http://dx.doi.org/ > .

DELMONT, E. et al. Multifocal motor neuropathy with and without conduction block: a single entity? Neurology, v. 67, n. 4, p. 592-6, Aug 22 2006. ISSN 0028-3878. Disponível em: < http://dx.doi.org/10.1212/01.wnl.0000234063.51897.20>.

DELMONT, E. et al. [Long-term follow-up of multifocal motor neuropathy with conduction block under intravenous immunoglobulin]. Rev Neurol (Paris), v. 163, n. 1, p. 82-8, Jan 2007. ISSN 0035-3787 (Print)0035-3787. Disponível em: < http://dx.doi.org/ >. 
DELMONT, E. et al. Do patients having a decrease in SNAP amplitude during the course of MMN present with a different condition? J Neurol, v. 256, n. 11, p. 1876-80, Nov 2009. ISSN 0340-5354. Disponível em: < http://dx.doi.org/10.1007/s00415-009-5217-0 >.

DEROIDE, N. et al. Triple-stimulation technique in multifocal neuropathy with conduction block. Muscle Nerve, v. 35, n. 5, p. 632-6, May 2007. ISSN 0148-639X (Print)0148-639x. Disponível em: < http://dx.doi.org/10.1002/mus.20742>.

DONAGHY, M. et al. Pure motor demyelinating neuropathy: deterioration after steroid treatment and improvement with intravenous immunoglobulin. J Neurol Neurosurg Psychiatry, v. 57, n. 7, p. 778-83, Jul 1994. ISSN 0022-3050 (Print)0022-3050. Disponível em: < http://dx.doi.org/ $>$.

ECHANIZ-LAGUNA, A.; DIETEMANN, J. L. Neurological picture. Seeing the blocks: MRI of the brachial plexus in multifocal motor neuropathy. J Neurol Neurosurg Psychiatry, v. 82, n. 7, p. 728, Jul 2011. ISSN 0022-3050. Disponível em: < http://dx.doi.org/10.1136/ jnnp.2010.239210>.

EFTIMOV, F.; VAN SCHAIK, I. N. Immunotherapy of multifocal motor neuropathy. Expert Opin Biol Ther, v. 11, n. 3, p. 329-42, Mar 2011. ISSN 1471-2598. Disponível em: < http://dx.doi.org/10.1517/14712598.2011.548798 >.

EURELINGS, M. et al. Antiganglioside antibodies in polyneuropathy associated with monoclonal gammopathy. Neurology, v. 57, n. 10, p. 1909-12, Nov 27 2001. ISSN 00283878 (Print)0028-3878. Disponível em: < http://dx.doi.org/ >.

European Federation of Neurological Societies/Peripheral Nerve Society guideline on management of multifocal motor neuropathy. Report of a joint task force of the European Federation of Neurological Societies and the Peripheral Nerve Society--first revision. J Peripher Nerv Syst, v. 15, n. 4, p. 295-301, Dec 2010. ISSN 1085-9489. Disponível em: < http://dx.doi.org/10.1111/j.1529-8027.2010.00290.x >.

FEDERICO, P. et al. Multifocal motor neuropathy improved by IVIg: randomized, doubleblind, placebo-controlled study. Neurology, v. 55, n. 9, p. 1256-62, Nov 14 2000. ISSN 00283878 (Print)0028-3878. Disponível em: < http://dx.doi.org/ >.

FERNANDEZ-MENENDEZ, S. et al. Multifocal-motor-neuropathy-like disease associated with Infliximab treatment in a patient with Crohn's disease. J Neurol Sci, v. 349, n. 1-2, p. 246-8, Feb 15 2015. ISSN 0022-510x. Disponível em: < http://dx.doi.org/10.1016/ j.jns.2015.01.003>.

FITZPATRICK, A. M. et al. An open label clinical trial of complement inhibition in multifocal motor neuropathy. J Peripher Nerv Syst, v. 16, n. 2, p. 84-91, Jun 2011. ISSN 1085-9489. Disponível em: < http://dx.doi.org/10.1111/j.1529-8027.2011.00328.x >. 
FRANSSEN, H. The node of Ranvier in multifocal motor neuropathy. J Clin Immunol, v. 34 Suppl 1, p. S105-11, Jul 2014. ISSN 0271-9142. Disponível em: < http://dx.doi.org/10.1007/ s10875-014-0023-6>.

FRANSSEN, H.; STRAVER, D. C. Pathophysiology of immune-mediated demyelinating neuropathies-part I: neuroscience. Muscle Nerve, v. 48, n. 6, p. 851-64, Dec 2013. ISSN 0148-639x. Disponível em: < http://dx.doi.org/10.1002/mus.24070 >.

GALASSI, G. et al. Cranial nerve involvement as presenting sign of multifocal motor neuropathy. J Clin Neurosci, v. 19, n. 12, p. 1733-5, Dec 2012. ISSN 0967-5868. Disponível em: < http://dx.doi.org/10.1016/j.jocn.2011.12.030>.

GONG, Y. et al. Localization of major gangliosides in the PNS: implications for immune neuropathies. Brain, v. 125, n. Pt 11, p. 2491-506, Nov 2002. ISSN 0006-8950 (Print)00068950. Disponível em: < http://dx.doi.org/ >.

GUIMARAES-COSTA, R.; BOMBELLI, F.; LEGER, J. M. Multifocal motor neuropathy. Curr Opin Neurol, v. 26, n. 5, p. 503-9, Oct 2013. ISSN 1350-7540. Disponível em: < http://dx.doi.org/10.1097/WCO.0b013e328364caca >.

HARBO, T. et al. Subcutaneous versus intravenous immunoglobulin in multifocal motor neuropathy: a randomized, single-blinded cross-over trial. Eur J Neurol, v. 16, n. 5, p. 631-8, May 2009. ISSN 1351-5101. Disponível em: < http://dx.doi.org/10.1111/j.14681331.2009.02568.x >.

HARSCHNITZ, O. et al. MMN: from immunological cross-talk to conduction block. J Clin Immunol, v. 34 Suppl 1, p. S112-9, Jul 2014. ISSN 0271-9142. Disponível em: < http://dx.doi.org/10.1007/s10875-014-0026-3 >.

HILLMEN, P. et al. The complement inhibitor eculizumab in paroxysmal nocturnal hemoglobinuria. N Engl J Med, v. 355, n. 12, p. 1233-43, Sep 21 2006. ISSN 0028-4793. Disponível em: < http://dx.doi.org/10.1056/NEJMoa061648>.

HOFMEIJER, J. et al. Why are sensory axons more vulnerable for ischemia than motor axons? PLoS One, v. 8, n. 6, p. e67113, 2013. ISSN 1932-6203. Disponível em: < http://dx.doi.org/10.1371/journal.pone.0067113>.

KAJI, R. Physiology of conduction block in multifocal motor neuropathy and other demyelinating neuropathies. Muscle Nerve, v. 27, n. 3, p. 285-96, Mar 2003. ISSN 0148639X (Print)0148-639x. Disponível em: < http://dx.doi.org/10.1002/mus.10273 >. 
KAJI, R. et al. Activity-dependent conduction block in multifocal motor neuropathy. Brain, v. 123 ( Pt 8), p. 1602-11, Aug 2000. ISSN 0006-8950 (Print)0006-8950. Disponível em: < http://dx.doi.org/ >.

KAJI, R. et al. Pathological findings at the site of conduction block in multifocal motor neuropathy. Ann Neurol, v. 33, n. 2, p. 152-8, Feb 1993. ISSN 0364-5134 (Print)0364-5134. Disponível em: < http://dx.doi.org/10.1002/ana.410330204 >.

KAJI, R.; SHIBASAKI, H.; KIMURA, J. Multifocal demyelinating motor neuropathy: cranial nerve involvement and immunoglobulin therapy. Neurology, v. 42, n. 3 Pt 1, p. 506-9, Mar 1992. ISSN 0028-3878 (Print)0028-3878. Disponível em: < http://dx.doi.org/ >.

KARAM, C. Correlates of outcome and response to IVIg in 88 patients with multifocal motor neuropathy. In: (Ed.). Neurology. United States, v.76, 2011. p.1194; author reply 1194-5. ISBN 1526-632X (Electronic)0028-3878 (Linking).

KATZ, J. S. et al. Electrophysiologic findings in multifocal motor neuropathy. Neurology, v. 48, n. 3, p. 700-7, Mar 1997. ISSN 0028-3878 (Print)0028-3878. Disponível em: < http://dx.doi.org/ >.

KIERNAN, M. C. et al. Evidence for axonal membrane hyperpolarization in multifocal motor neuropathy with conduction block. Brain, v. 125, n. Pt 3, p. 664-75, Mar 2002. ISSN 0006-8950 (Print)0006-8950. Disponível em: < http://dx.doi.org/ >.

KORNBERG, A. J.; PESTRONK, A. The clinical and diagnostic role of anti-GM1 antibody testing. Muscle Nerve, v. 17, n. 1, p. 100-4, Jan 1994. ISSN 0148-639X (Print)0148-639x. Disponível em: < http://dx.doi.org/10.1002/mus.880170115>.

KOSKI, C. L. Treatment of multifocal motor neuropathy with intravenous immunoglobulin. $\mathbf{J}$ Clin Immunol, v. 34 Suppl 1, p. S127-31, Jul 2014. ISSN 0271-9142. Disponível em: < http://dx.doi.org/10.1007/s10875-014-0016-5>.

KYRIAKIDES, T. et al. Sleep hypoventilation syndrome and respiratory failure due to multifocal motor neuropathy with conduction block. Muscle Nerve, v. 43, n. 4, p. 610-4, Apr 2011. ISSN 0148-639x. Disponível em: < http://dx.doi.org/10.1002/mus.21994 >.

LAMBRECQ, V. et al. Sensory loss in multifocal motor neuropathy: a clinical and electrophysiological study. Muscle Nerve, v. 39, n. 2, p. 131-6, Feb 2009. ISSN 0148-639X (Print)0148-639x. Disponível em: < http://dx.doi.org/10.1002/mus.21163>.

LEGER, J. M. et al. Intravenous immunoglobulin therapy in multifocal motor neuropathy: a double-blind, placebo-controlled study. Brain, v. 124, n. Pt 1, p. 145-53, Jan 2001. ISSN 0006-8950 (Print)0006-8950. Disponível em: < http://dx.doi.org/ >. 
LEGER, J. M.; GUIMARAES-COSTA, R.; IANCU FERFOGLIA, R. The pathogenesis of multifocal motor neuropathy and an update on current management options. Ther Adv Neurol Disord, v. 8, n. 3, p. 109-22, May 2015. ISSN 1756-2856 (Print)1756-2856. Disponível em: < http://dx.doi.org/10.1177/1756285615575269>.

LEGER, J. M. et al. Intravenous immunoglobulin as short- and long-term therapy of multifocal motor neuropathy: a retrospective study of response to IVIg and of its predictive criteria in 40 patients. J Neurol Neurosurg Psychiatry, v. 79, n. 1, p. 93-6, Jan 2008. ISSN 0022-3050. Disponível em: < http://dx.doi.org/10.1136/jnnp.2007.121756>.

LIEVENS, I. et al. [Multifocal motor neuropathy: a retrospective study of sensory nerve conduction velocities in long-term follow-up of 21 patients]. Rev Neurol (Paris), v. 165, n. 3, p. 243-8, Mar 2009. ISSN 0035-3787 (Print)0035-3787. Disponível em: < http://dx.doi. org/10.1016/j.neurol.2008.10.018>.

LIN, C. S. et al. Responses of human sensory and motor axons to the release of ischaemia and to hyperpolarizing currents. J Physiol, v. 541, n. Pt 3, p. 1025-39, Jun 15 2002. ISSN 0022-3751 (Print)0022-3751. Disponível em: < http://dx.doi.org/ >.

MCGONIGAL, R. et al. Anti-GD1a antibodies activate complement and calpain to injure distal motor nodes of Ranvier in mice. Brain, v. 133, n. Pt 7, p. 1944-60, Jul 2010. ISSN 0006-8950. Disponível em: < http://dx.doi.org/10.1093/brain/awq119 >.

MEUCCI, N. et al. Long term effect of intravenous immunoglobulins and oral cyclophosphamide in multifocal motor neuropathy. J Neurol Neurosurg Psychiatry, v. 63, n. 6, p. 765-9, Dec 1997. ISSN 0022-3050 (Print)0022-3050. Disponível em: < http://dx.doi.org/ >.

MEUTH, S. G.; KLEINSCHNITZ, C. Multifocal motor neuropathy: update on clinical characteristics, pathophysiological concepts and therapeutic options. Eur Neurol, v. 63, n. 4, p. 193-204, 2010. ISSN 0014-3022. Disponível em: < http://dx.doi.org/10.1159/000282734 $>$.

MORONI, I. et al. Childhood-onset multifocal motor neuropathy with conduction blocks. Neurology, v. 66, n. 6, p. 922-4, Mar 28 2006. ISSN 0028-3878. Disponível em: < http://dx.doi.org/10.1212/01.wnl.0000203346.25068.3f >.

MULEY, S. A.; PARRY, G. J. Multifocal motor neuropathy. J Clin Neurosci, v. 19, n. 9, p. 1201-9, Sep 2012. ISSN 0967-5868. Disponível em: < http://dx.doi.org/10.1016/j.jocn. 2012.02.011>.

NEMNI, R. et al. Efficacy of cyclosporine treatment in multifocal motor neuropathy. $\mathbf{J}$ Neurol, v. 250, n. 9, p. 1118-20, Sep 2003. ISSN 0340-5354 (Print)0340-5354. Disponível em: < http://dx.doi.org/10.1007/s00415-003-0131-3 >. 
NOBILE-ORAZIO, E. Multifocal motor neuropathy. J Neuroimmunol, v. 115, n. 1-2, p. 418, Apr 2 2001. ISSN 0165-5728 (Print)0165-5728. Disponível em: < http://dx.doi.org/ >.

NOBILE-ORAZIO, E.; CAPPELLARI, A.; PRIORI, A. Multifocal motor neuropathy: current concepts and controversies. Muscle Nerve, v. 31, n. 6, p. 663-80, Jun 2005. ISSN 0148-639X (Print)0148-639x. Disponível em: < http://dx.doi.org/10.1002/mus.20296>.

NOBILE-ORAZIO, E.; GIANNOTTA, C.; BRIANI, C. Anti-ganglioside complex IgM antibodies in multifocal motor neuropathy and chronic immune-mediated neuropathies. J Neuroimmunol, v. 219, n. 1-2, p. 119-22, Feb 26 2010. ISSN 0165-5728. Disponível em: < http://dx.doi.org/10.1016/j.jneuroim.2009.11.012>.

O'HANLON, G. M. et al. Calpain inhibitors protect against axonal degeneration in a model of anti-ganglioside antibody-mediated motor nerve terminal injury. Brain, v. 126, n. Pt 11, p. 2497-509, Nov 2003. ISSN 0006-8950 (Print)0006-8950. Disponível em: < http://dx.doi. org/10.1093/brain/awg254 >.

OGAWA-GOTO, K.; ABE, T. Gangliosides and glycosphingolipids of peripheral nervous system myelins--a minireview. Neurochem Res, v. 23, n. 3, p. 305-10, Mar 1998. ISSN 0364-3190 (Print)0364-3190. Disponível em: < http://dx.doi.org/ >.

OGAWA-GOTO, K. et al. Different ceramide compositions of gangliosides between human motor and sensory nerves. J Neurochem, v. 55, n. 5, p. 1486-93, Nov 1990. ISSN 0022-3042 (Print)0022-3042. Disponível em: < http://dx.doi.org/ >.

OGAWA-GOTO, K. et al.Myelin gangliosides of human peripheral nervous system: an enrichment of GM1 in the motor nerve myelin isolated from cauda equina. J Neurochem, v. 59, n. 5, p. 1844-9, Nov 1992. ISSN 0022-3042 (Print)0022-3042. Disponível em: < http://dx.doi.org/ >.

OLNEY, R. K. et al. Consensus criteria for the diagnosis of multifocal motor neuropathy. Muscle Nerve, v. 27, n. 1, p. 117-21, Jan 2003. ISSN 0148-639X (Print)0148-639x. Disponível em: < http://dx.doi.org/10.1002/mus.10317>.

PARRY, G. J. Are multifocal motor neuropathy and Lewis-Sumner syndrome distinct nosologic entities? In: (Ed.). Muscle Nerve. United states, v.22, 1999. p.557-9. ISBN 0148639X (Print)0148-639X (Linking).

PARRY, G. J.; CLARKE, S. Multifocal acquired demyelinating neuropathy masquerading as motor neuron disease. Muscle Nerve, v. 11, n. 2, p. 103-7, Feb 1988. ISSN 0148-639X (Print)0148-639x. Disponível em: < http://dx.doi.org/10.1002/mus.880110203 >. 
PESTRONK, A. et al. Multifocal motor neuropathy: serum IgM binding to a GM1 ganglioside-containing lipid mixture but not to GM1 alone. Neurology, v. 48, n. 4, p. 1104-6, Apr 1997. ISSN 0028-3878 (Print)0028-3878. Disponível em: < http://dx.doi.org/ >.

PESTRONK, A.; CHUQUILIN, M.; CHOKSI, R. Motor neuropathies and serum IgM binding to NS6S heparin disaccharide or GM1 ganglioside. J Neurol Neurosurg Psychiatry, v. 81, n. 7, p. 726-30, Jul 2010. ISSN 0022-3050. Disponível em: < http://dx.doi.org/ 10.1136/jnnp.2009.202796>.

PESTRONK, A. et al. A treatable multifocal motor neuropathy with antibodies to GM1 ganglioside. Ann Neurol, v. 24, n. 1, p. 73-8, Jul 1988. ISSN 0364-5134 (Print)0364-5134. Disponível em: < http://dx.doi.org/10.1002/ana.410240113>.

PIEPERS, S. et al. Mycophenolate mofetil as adjunctive therapy for MMN patients: a randomized, controlled trial. Brain, v. 130, n. Pt 8, p. 2004-10, Aug 2007. ISSN 0006-8950. Disponível em: < http://dx.doi.org/10.1093/brain/awm144 >.

PRINGLE, C. E. et al. Multifocal motor neuropathy presenting as ophthalmoplegia. Muscle Nerve, v. 20, n. 3, p. 347-51, Mar 1997. ISSN 0148-639X (Print)0148-639x. Disponível em: $<$ http://dx.doi.org/10.1002/(sici)1097-4598(199703)20:3<347::aid-mus12>3.0.co >.

PRIORI, A. et al. Pathophysiological heterogeneity of conduction blocks in multifocal motor neuropathy. Brain, v. 128, n. Pt 7, p. 1642-8, Jul 2005. ISSN 0006-8950. Disponível em: < http://dx.doi.org/10.1093/brain/awh513>.

RACK, P. M.; FOX, J. E. The effects of cold on a partially denervated muscle. J Neurol Neurosurg Psychiatry, v. 50, n. 4, p. 460-4, Apr 1987. ISSN 0022-3050 (Print)0022-3050. Disponível em: < http://dx.doi.org/ >.

RAMDAS, S. et al. Acute motor neuropathy with pure distal involvement--a case report of multifocal motor neuropathy. Eur J Paediatr Neurol, v. 17, n. 4, p. 415-8, Jul 2013. ISSN 1090-3798. Disponível em: < http://dx.doi.org/10.1016/j.ejpn.2012.12.005 >.

RASMINSKY, M. The effects of temperature on conduction in demyelinated single nerve fibers. Arch Neurol, v. 28, n. 5, p. 287-92, May 1973. ISSN 0003-9942 (Print)0003-9942. Disponível em: $<$ http://dx.doi.org/ $>$.

REID, G. et al. Human axons contain at least five types of voltage-dependent potassium channel. J Physiol, v. 518 ( Pt 3), p. 681-96, Aug 1 1999. ISSN 0022-3751 (Print)0022-3751. Disponível em: $<$ http://dx.doi.org/ $>$.

RHEE, E. K.; ENGLAND, J. D.; SUMNER, A. J. A computer simulation of conduction block: effects produced by actual block versus interphase cancellation. Ann Neurol, v. 28, n. 2, p. 146-56, Aug 1990. ISSN 0364-5134 (Print)0364-5134. Disponível em: < http://dx.doi.org/10.1002/ana.410280206>. 
ROWAN, C. R.; TUBRIDY, N.; CULLEN, G. Multifocal Motor Neuropathy Associated with Infliximab. In: (Ed.). J Crohns Colitis. England: please email: journals. permissions@oup.com., v.9, 2015. p.1174-5. ISBN 1876-4479 (Electronic)1873-9946 (Linking).

SANTORO, M. et al. Experimental conduction block induced by serum from a patient with anti-GM1 antibodies. Ann Neurol, v. 31, n. 4, p. 385-90, Apr 1992. ISSN 0364-5134 (Print)0364-5134. Disponível em: < http://dx.doi.org/10.1002/ana.410310407 >.

SCHWARZ, J. R.; EIKHOF, G. Na currents and action potentials in rat myelinated nerve fibres at 20 and 37 degrees C. Pflugers Arch, v. 409, n. 6, p. 569-77, Aug 1987. ISSN 00316768 (Print)0031-6768. Disponível em: < http://dx.doi.org/ >.

SHIMIZU, F. et al. Sera from patients with multifocal motor neuropathy disrupt the bloodnerve barrier. J Neurol Neurosurg Psychiatry, v. 85, n. 5, p. 526-37, May 2014. ISSN 00223050. Disponível em: < http://dx.doi.org/10.1136/jnnp-2013-305405 >.

SLEE, M.; SELVAN, A.; DONAGHY, M. Multifocal motor neuropathy: the diagnostic spectrum and response to treatment. Neurology, v. 69, n. 17, p. 1680-7, Oct 23 2007. ISSN 0028-3878. Disponível em: < http://dx.doi.org/10.1212/01.wnl.0000277697.55288.d0 >.

STANGEL, M. et al. Side effects of intravenous immunoglobulins in neurological autoimmune disorders--a prospective study. J Neurol, v. 250, n. 7, p. 818-21, Jul 2003. ISSN 0340-5354 (Print)0340-5354. Disponível em: < http://dx.doi.org/10.1007/s00415-003-1085-1 $>$.

STERN, B. V. et al. Multifocal motor neuropathy with conduction block associated with metastatic lymphoma of the nervous system. J Neurooncol, v. 78, n. 1, p. 81-4, May 2006. ISSN 0167-594X (Print)0167-594x. Disponível em: < http://dx.doi.org/10.1007/s11060-0059060-6>.

STRAVER, D. C. et al. Cold paresis in multifocal motor neuropathy. J Neurol, v. 258, n. 2, p. 212-7, Feb 2011. ISSN 0340-5354. Disponível em: < http://dx.doi.org/10.1007/s00415$010-5712-3>$.

STRAVER, D. C. et al. Activity-dependent conduction block in multifocal motor neuropathy. Muscle Nerve, v. 43, n. 1, p. 31-6, Jan 2011. ISSN 0148-639x. Disponível em: < http://dx.doi.org/10.1002/mus.21843>.

SUNDERLAND, S. The anatomy and physiology of nerve injury. Muscle Nerve, v. 13, n. 9, p. 771-84, Sep 1990. ISSN 0148-639X (Print)0148-639x. Disponível em: < http://dx.doi.org/ 10.1002/mus.880130903>. 
SUSUKI, K. et al. Anti-GM1 antibodies cause complement-mediated disruption of sodium channel clusters in peripheral motor nerve fibers. J Neurosci, v. 27, n. 15, p. 3956-67, Apr 11 2007. ISSN 0270-6474. Disponível em: < http://dx.doi.org/10.1523/jneurosci.4401-06.2007 >.

SUSUKI, K. et al. Dysfunction of nodes of Ranvier: a mechanism for anti-ganglioside antibody-mediated neuropathies. Exp Neurol, v. 233, n. 1, p. 534-42, Jan 2012. ISSN 00144886. Disponível em: < http://dx.doi.org/10.1016/j.expneurol.2011.11.039>.

SUTEDJA, N. A. et al. Increased frequency of HLA-DRB $1 * 15$ in patients with multifocal motor neuropathy. 2010-03-09 2010. Disponível em: < http://www.neurology.org/content/ 74/10/828.short?sid=d5c24521-3161-474f-8e3b-50ac394a72e 2 >.

TAKIGAWA, T. et al. Antibodies against GM1 ganglioside affect $\mathrm{K}+$ and $\mathrm{Na}+$ currents in isolated rat myelinated nerve fibers. Ann Neurol, v. 37, n. 4, p. 436-42, Apr 1995. ISSN 0364-5134 (Print)0364-5134. Disponível em: < http://dx.doi.org/10.1002/ana.410370405>.

TAYLOR, B. V. et al. Multifocal motor neuropathy: pathologic alterations at the site of conduction block. J Neuropathol Exp Neurol, v. 63, n. 2, p. 129-37, Feb 2004. ISSN 00223069 (Print)0022-3069. Disponível em: < http://dx.doi.org/ >.

TAYLOR, B. V.; GROSS, L.; WINDEBANK, A. J. The sensitivity and specificity of antiGM1 antibody testing. Neurology, v. 47, n. 4, p. 951-5, Oct 1996. ISSN 0028-3878 (Print)0028-3878. Disponível em: < http://dx.doi.org/ >.

TAYLOR, B. V. et al. Natural history of 46 patients with multifocal motor neuropathy with conduction block. Muscle Nerve, v. 23, n. 6, p. 900-8, Jun 2000. ISSN 0148-639X (Print)0148-639x. Disponível em: < http://dx.doi.org/ > .

TERENGHI, F. et al. Multifocal motor neuropathy and Campylobacter jejuni reactivity. Neurology, v. 59, n. 2, p. 282-4, Jul 23 2002. ISSN 0028-3878 (Print)0028-3878. Disponível em: < http://dx.doi.org/ $>$.

TERENGHI, F. et al. How long is IVIg effective in multifocal motor neuropathy? Neurology, v. 62, n. 4, p. 666-8, Feb 24 2004. ISSN 0028-3878. Disponível em: < http://dx.doi.org/ >.

VAN ASSELDONK, J. T. et al. Axon loss is an important determinant of weakness in multifocal motor neuropathy. J Neurol Neurosurg Psychiatry, v. 77, n. 6, p. 743-7, Jun 2006. ISSN 0022-3050. Disponível em: < http://dx.doi.org/10.1136/jnnp.2005.064816>.

VAN ASSELDONK, J. T. et al. Demyelination and axonal loss in multifocal motor neuropathy: distribution and relation to weakness. Brain, v. 126, n. Pt 1, p. 186-98, Jan 2003. ISSN 0006-8950 (Print)0006-8950. Disponível em: < http://dx.doi.org/ > . 
VAN ASSELDONK, J. T. et al. Criteria for conduction block based on computer simulation studies of nerve conduction with human data obtained in the forearm segment of the median nerve. Brain, v. 129, n. Pt 9, p. 2447-60, Sep 2006. ISSN 0006-8950. Disponível em: < http://dx.doi.org/10.1093/brain/awl197 >.

VAN DEN BERG, L. H. et al. Treatment of multifocal motor neuropathy with high dose intravenous immunoglobulins: a double blind, placebo controlled study. J Neurol Neurosurg Psychiatry, v. 59, n. 3, p. 248-52, Sep 1995. ISSN 0022-3050 (Print)0022-3050. Disponível em: < http://dx.doi.org/ $>$.

VAN DEN BERG-VOS, R. M. et al. Multifocal motor neuropathy: long-term clinical and electrophysiological assessment of intravenous immunoglobulin maintenance treatment. Brain, v. 125, n. Pt 8, p. 1875-86, Aug 2002. ISSN 0006-8950 (Print)0006-8950. Disponível em: < http://dx.doi.org/ $>$.

VAN DEN BERG-VOS, R. M. et al. Multifocal motor neuropathy: diagnostic criteria that predict the response to immunoglobulin treatment. Ann Neurol, v. 48, n. 6, p. 919-26, Dec 2000. ISSN 0364-5134 (Print)0364-5134. Disponível em: < http://dx.doi.org/ >.

VAN DEN BERG-VOS, R. M. et al. Multifocal inflammatory demyelinating neuropathy: a distinct clinical entity? Neurology, v. 54, n. 1, p. 26-32, Jan 11 2000. ISSN 0028-3878 (Print)0028-3878. Disponível em: < http://dx.doi.org/ >.

VAN DEN BERGH, P. Y. et al. European Federation of Neurological Societies/Peripheral Nerve Society guideline on management of chronic inflammatory demyelinating polyradiculoneuropathy: report of a joint task force of the European Federation of Neurological Societies and the Peripheral Nerve Society - first revision. Eur J Neurol, v. 17, n. 3, p. 356-63, Mar 2010. ISSN 1351-5101. Disponível em: < http://dx.doi.org/10.1111/ j.1468-1331.2009.02930.x >.

VAN ES, H. W. et al. Magnetic resonance imaging of the brachial plexus in patients with multifocal motor neuropathy. Neurology, v. 48, n. 5, p. 1218-24, May 1997. ISSN 0028-3878 (Print)0028-3878. Disponível em: < http://dx.doi.org/ >.

VAN SCHAIK, I. N. et al. Intravenous immunoglobulin for multifocal motor neuropathy. Cochrane Database Syst Rev, n. 2, p. Cd004429, 2005. ISSN 1361-6137. Disponível em: < http://dx.doi.org/10.1002/14651858.CD004429.pub2 >.

VANHOUTTE, E. K. et al. Modifying the Medical Research Council grading system through Rasch analyses. Brain, v. 135, n. Pt 5, p. 1639-49, May 2012. ISSN 0006-8950. Disponível em: < http://dx.doi.org/10.1093/brain/awr318 >. 
VERSCHUEREN, A. et al. Lewis-Sumner syndrome and multifocal motor neuropathy. Muscle Nerve, v. 31, n. 1, p. 88-94, Jan 2005. ISSN 0148-639X (Print)0148-639x. Disponível em: < http://dx.doi.org/10.1002/mus.20236>.

VISSER, J. et al. Mimic syndromes in sporadic cases of progressive spinal muscular atrophy. Neurology, v. 58, n. 11, p. 1593-6, Jun 11 2002. ISSN 0028-3878 (Print)0028-3878. Disponível em: < http://dx.doi.org/ $>$.

VLAM, L. et al. Multifocal motor neuropathy: diagnosis, pathogenesis and treatment strategies. Nat Rev Neurol, v. 8, n. 1, p. 48-58, Jan 2012. ISSN 1759-4758. Disponível em: < http://dx.doi.org/10.1038/nrneurol.2011.175 >.

VUCIC, S. et al. Multifocal motor neuropathy: decrease in conduction blocks and reinnervation with long-term IVIg. Neurology, v. 63, n. 7, p. 1264-9, Oct 12 2004. ISSN 0028-3878. Disponível em: < http://dx.doi.org/ >.

WAXMAN, S. G. Axonal conduction and injury in multiple sclerosis: the role of sodium channels. Nat Rev Neurosci, v. 7, n. 12, p. 932-41, Dec 2006. ISSN 1471-003X (Print)1471003x. Disponível em: < http://dx.doi.org/10.1038/nrn2023>.

WAXMAN, S. G. et al. Anoxic injury of rat optic nerve: ultrastructural evidence for coupling between $\mathrm{Na}+$ influx and $\mathrm{Ca}(2+)$-mediated injury in myelinated CNS axons. Brain Res, v. 644, n. 2, p. 197-204, May 2 1994. ISSN 0006-8993 (Print)0006-8993. Disponível em: < http://dx.doi.org/ >.

WILLISON, H. J.; YUKI, N. Peripheral neuropathies and anti-glycolipid antibodies. Brain, v. 125, n. Pt 12, p. 2591-625, Dec 2002. ISSN 0006-8950 (Print)0006-8950. Disponível em: < http://dx.doi.org/ >.

WITTSTOCK, M.; BENECKE, R.; ZETTL, U. K. Therapy with intravenous immunoglobulins: complications and side-effects. Eur Neurol, v. 50, n. 3, p. 172-5, 2003. ISSN 0014-3022 (Print)0014-3022. Disponível em: < http://dx.doi.org/73059>.

YUKI, N. Acute motor axonal neuropathy and multifocal motor neuropathy: more in common than not. Muscle Nerve, v. 48, n. 5, p. 693-5, Nov 2013. ISSN 0148-639x. Disponível em: < http://dx.doi.org/10.1002/mus.23871 >.

YUKI, N. et al. IVIG blocks complement deposition mediated by anti-GM1 antibodies in multifocal motor neuropathy. J Neurol Neurosurg Psychiatry, v. 82, n. 1, p. 87-91, Jan 2011. ISSN 0022-3050. Disponível em: < http://dx.doi.org/10.1136/jnnp.2010.205856 >. 